\title{
A series of mitochondria/lysosomes self-targetable near-infrared hemicyanine dyes for viscosity detection
}

\author{
Xiu-Zhi Yang, ${ }^{\dagger}$ Bing Xu, ${ }^{\ddagger}$ Lei Shen,${ }^{\S}$ Ru Sun, ${ }^{* \dagger}$ Yu-Jie Xu, ${ }^{\dagger}$ Ying-Lin Song, ${ }^{\S}$ Jian-Feng Ge e ${ }^{* \dagger,}, \|$ \\ †College of Chemistry, Che mical Engineering and Material Science, Soochow University, 199 Ren’Ai Road, Suzhou 215123, China; ${ }^{\ddagger}$ \\ School of Radiation Medicine and Protection, Medical College of Soochow University, Soochow University, Suzhou 215123, China; \\ ${ }^{\S}$ Department of Physics, Soochow University, Suzhou 215123, China \\ "Jiangsu Key Laboratory of Medical Optics, Suzhou Institute of Biomedical Engineering and Technology, Chinese Academy of \\ Sciences, Suzhou 215163, People's Republic of China \\ *E-mail: sunru924@hotmail.com (R.Sun); ge_jianfeng@hotmail.com (J.-F.Ge).
}

\section{Index}

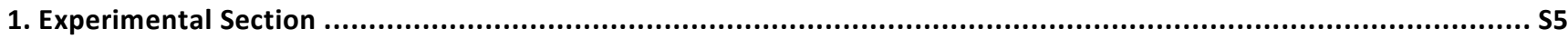

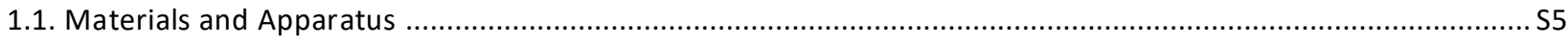

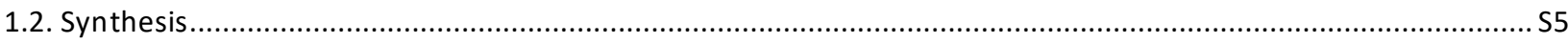

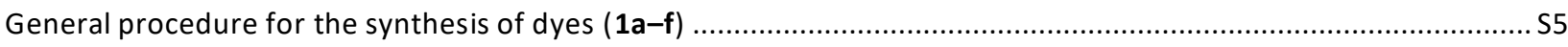

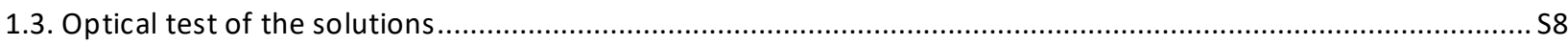

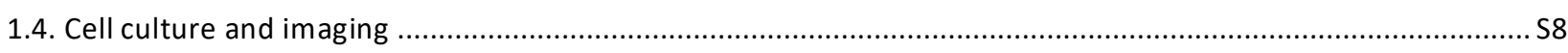

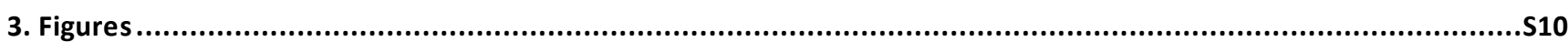

Figure S1. Optical spectra of dye $\mathbf{1 b}(10 \mu \mathrm{M})$ in different ratios of glycerol-PBS mixtures containing $1 \%$ DMSO (0.89 cP$856 \mathrm{cP})$ : (a) absorption spectrum, insert: the color change of dye $\mathbf{1 b}$ in PBS and glycerol under daylight. (b) Fluorescence spectrum, insert photograph showed dye $\mathbf{1 b}$ in PBS and glycerol under a $365 \mathrm{~nm}$ lamp in darkroom, $\lambda$ ex $=$ $605 \mathrm{~nm}$, slit widths: $3 \mathrm{~nm} / 5 \mathrm{~nm}$. (c) Relationship between $\mathrm{lg}$ (I $685 \mathrm{~nm}$ ) and Ig $\eta$; (d) linear relationship between lg (I $685 \mathrm{~nm})$ and $\lg \eta$, the data were shown as mean $\pm S D(n=3)$. S10

Figure S2. Optical spectra of dye $1 c(10 \mu \mathrm{M})$ in different ratios of glycerol-PBS mixtures containing $1 \%$ DMSO (0.89 cP$856 \mathrm{cP}$ ): (a) absorption spectrum, insert: the color change of dye 1c in PBS and glycerol under daylight. (b) Fluorescence spectrum, insert photograph showed dye 1c in PBS and glycerol under a $365 \mathrm{~nm}$ lamp in darkroom, $\lambda_{e x}=605 \mathrm{~nm}$, slit widths: $3 \mathrm{~nm} / 3 \mathrm{~nm}$. (c) Relationship between $\mathrm{lg}(\mathrm{I} 684 \mathrm{~nm})$ and $\mathrm{lg} \eta$; (d) linear relationship between $\mathrm{lg}(\mathrm{I} 684 \mathrm{~nm})$ and $\mathrm{lg} \eta$, the data were shown as mean $\pm S D(n=3)$. S10 
Figure S3. Optical spectra of dye $1 \mathrm{~d}(10 \mu \mathrm{M})$ in different ratios of glycerol-PBS mixtures containing $1 \%$ DMSO (0.89 cP$856 \mathrm{cP})$ : (a) absorption spectrum, insert: the color change of dye $1 \mathrm{~d}$ in PBS and glycerol under daylight. (b) Fluorescence spectrum, insert photograph showed dye 1d in PBS and glycerol under a $365 \mathrm{~nm}$ lamp in darkroom, $\lambda$ ex $=$

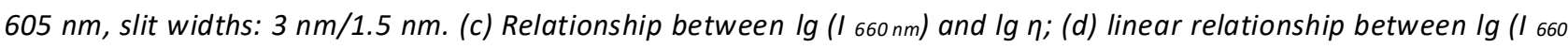
$n m$ ) and $\lg \eta$, the data were shown as mean $\pm S D(n=3)$.

Figure S4. Optical spectra of dye 1 e $(10 \mu \mathrm{M})$ in different ratios of glycerol-PBS mixtures containing $1 \%$ DMSO (0.89 cP$856 \mathrm{cP})$ : (a) absorption spectrum, insert: the color change of dye $1 e$ in PBS and glycerol under daylight. (b) Fluorescence spectrum, insert photograph showed dye 1e in PBS and glycerol under a $365 \mathrm{~nm}$ lamp in darkroom, $\lambda_{\text {ex }}=$ $605 \mathrm{~nm}$, slit widths: $3 \mathrm{~nm} / 3 \mathrm{~nm}$. (c) Relationship between $\mathrm{g}$ (I $683 \mathrm{~nm}$ ) and Ig $\eta$; (d) linear relationship between lg (I $683 \mathrm{~nm})$ and $\lg \eta$, the data were shown as mean $\pm S D(n=3)$. S11

Figure S5. Optical spectra of dye $1 f(10 \mu \mathrm{M})$ in different ratios of glycerol-PBS mixtures containing $1 \%$ DMSO (0.89 cP$856 \mathrm{cP}$ ): (a) absorption spectrum, insert: the color change of dye $1 \mathrm{f}$ in PBS and glycerol under daylight. (b) fluorescence spectrum, insert photograph showed dye $1 \mathrm{f}$ in PBS and glycerol under a $365 \mathrm{~nm}$ lamp in darkroom, $\lambda_{e x}=605 \mathrm{~nm}$, slit widths: $3 \mathrm{~nm} / 3 \mathrm{~nm}$. (c) Relationship between $\mathrm{lg}(\mathrm{I} 690 \mathrm{~nm})$ and $\mathrm{lg} \eta$; (d) linear relationship between $\mathrm{lg}(\mathrm{I} 690 \mathrm{~nm})$ and $\mathrm{lg} \eta$, the data were shown as mean $\pm S D(n=3)$.

Figure S6. (a) Fluorescence responses of dye 1a $(10 \mu \mathrm{M})$ in the presence of $100 \mu \mathrm{M}$ of different biologically relevant analytes for $1 \mathrm{~h}$; (b) fluorescence intensity of dye $1 \mathrm{a}(10 \mu \mathrm{M})$ at different $\mathrm{pH}$ values in B-R buffer containing 50\% glycerol $\left(\lambda_{e x}=605 \mathrm{~nm}\right.$, slit widths: $\left.3 \mathrm{~nm} / 5 \mathrm{~nm}\right)$, the data were shown as mean $\pm S D(n=3)$. S13

Figure S7. (a) Fluorescence responses of dye $1 \mathrm{~b}(10 \mu \mathrm{M})$ in the presence of $100 \mu \mathrm{M}$ of different biologically relevant analytes for $1 \mathrm{~h}$; (b) fluorescence intensity of dye $1 \mathrm{~b}(10 \mu \mathrm{M})$ at different $\mathrm{pH}$ values in B-R buffer containing 50\% glycerol $\left(\lambda_{e x}=605 \mathrm{~nm}\right.$, slit widths: $\left.3 \mathrm{~nm} / 5 \mathrm{~nm}\right)$, the data were shown as mean $\pm S D(n=3)$.

Figure S8. (a) Fluorescence responses of dye $1 \mathrm{c}(10 \mu \mathrm{M})$ in the presence of $100 \mu \mathrm{M}$ of different biologically relevant analytes for $1 \mathrm{~h}$; (b) fluorescence intensity of dye $1 \mathrm{c}(10 \mu \mathrm{M})$ at different $p H$ values in $B-R$ buffer containing $50 \%$ glycerol $\left(\lambda_{e x}=605 \mathrm{~nm}\right.$, slit widths: $\left.3 \mathrm{~nm} / 3 \mathrm{~nm}\right)$, the data were shown as mean $\pm S D(n=3)$. S13

Figure 59. (a) Fluorescence responses of dye $1 d(10 \mu \mathrm{M})$ in the presence of $100 \mu \mathrm{M}$ of different biologically relevant analytes for $1 \mathrm{~h}$; (b) fluorescence intensity of dye $1 \mathrm{~d}(10 \mu \mathrm{M})$ at different $\mathrm{pH}$ values in $\mathrm{B}-\mathrm{R}$ buffer containing $50 \%$ glycerol ( $\lambda_{e x}=605 \mathrm{~nm}$, slit widths: $\left.3 \mathrm{~nm} / 1.5 \mathrm{~nm}\right)$, the data were shown as mean $\pm S D(n=3)$ S14

Figure S10. (a) Fluorescence responses of dye 1 e $(10 \mu \mathrm{M})$ in the presence of $100 \mu \mathrm{M}$ of different biologically relevant analytes for $1 \mathrm{~h}$; (b) fluorescence intensity of dye 1 e $(10 \mu \mathrm{M})$ at different $\mathrm{pH}$ values in $\mathrm{B}-\mathrm{R}$ buffer containing $50 \%$ glycerol $\left(\lambda_{e x}=605 \mathrm{~nm}\right.$, slit widths: $\left.3 \mathrm{~nm} / 3 \mathrm{~nm}\right)$, the data were shown as mean $\pm S D(n=3)$. S14

Figure S11. (a) Fluorescence responses of dye $1 f(10 \mu \mathrm{M})$ in the presence of $100 \mu \mathrm{M}$ of different biologically relevant analytes for $1 \mathrm{~h}$; (b) fluorescence intensity of dye $1 \mathrm{f}(10 \mu \mathrm{M})$ at different $\mathrm{pH}$ values in $\mathrm{B}-\mathrm{R}$ buffer containing $50 \%$ glycerol $\left(\lambda_{e x}=605 \mathrm{~nm}\right.$, slit widths: $\left.3 \mathrm{~nm} / 3 \mathrm{~nm}\right)$, the data were shown as mean $\pm S D(n=3)$.

Figure S12. Fluorescence spectra of dyes 1a-f in various solvents with different polarities: (a) dye 1a, $\lambda_{e x}=605 \mathrm{~nm}$, slit widths: $3 \mathrm{~nm} / 5 \mathrm{~nm}$; (b) dye 1b, $\lambda_{\text {ex }}=605 \mathrm{~nm}$, slit widths: $3 \mathrm{~nm} / 5 \mathrm{~nm}$; (c) dye 1c, $\lambda_{\text {ex }}=605 \mathrm{~nm}$, slit widths: $3 \mathrm{~nm} / 3 \mathrm{~nm}$; 
(d) dye 1d, $\lambda_{e x}=605 \mathrm{~nm}$, slit widths: $3 \mathrm{~nm} / 1.5 \mathrm{~nm}$; (e) dye 1e, $\lambda_{e x}=605 \mathrm{~nm}$, slit widths: $3 \mathrm{~nm} / 3 \mathrm{~nm}$; (f) dye 1f, $\lambda_{e x}=605$ $\mathrm{nm}$, slit widths: $3 \mathrm{~nm} / 3 \mathrm{~nm}$.

Figure S13. Fluorescence confocal images of HeLa cells with dye $\mathbf{1 b}$ and their ROls analysis. (a) Bright-field transmission images; (b) confocal images (green channel) of cells with LysoTracker Green DND-26 (100 nM); (c) confocal images (red channel) of cells with dye 1b; (d) merged images of (b) and (c); (e) fluorescence intensities of the regions of interest (ROIs) in (b) and (c); (f) fluorescence intensity correlation plot.

Figure S14. Fluorescence confocal images of HeLa cells with dye 1c and their ROls analysis. (a) Bright-field transmission images; (b) confocal images (green channel) of cells with LysoTracker Green DND-26 (100 nM); (c) confocal images (red channel) of cells with dye 1c; (d) merged images of (b) and (c); (e) fluorescence intensities of the regions of interest (ROIs) in (b) and (c); (f) fluorescence intensity correlation plot. S16

Figure S15. Fluorescence confocal images of HeLa cells with dye $1 \boldsymbol{e}$ and their ROls analysis. (a) Bright-field transmission images; (b) confocal images (green channel) of cells with MitoTracker Green FM (100 nM); (c) confocal images (red channel) of cells with dye 1e; (d) merged images of (b) and (c); (e) fluorescence intensities of the regions of interest (ROIs) in (b) and (c); (f) fluorescence intensity correlation plot. ..S17

Figure S16. Fluorescence confocal images of HeLa cells with dye 1 f and their ROIs analysis. (a) Bright-field transmission images; (b) confocal images (green channel) of cells with MitoTracker Green FM (100 nM); (c) confocal images (red channel) of cells with dye 1f; (d) merged images of (b) and (c); (e) fluorescence intensities of the regions of interest (ROIs) in (b) and (c); (f) fluorescence intensity correlation plot. S17

Figure S17. Confocal laser fluorescence images of HeLa cells: (a-c) HeLa cells incubated with dye 1 b (1 $\mu$ M) for 20 min; (d-f) HeLa cells treated with dexamethasone $(10 \mu \mathrm{M})$ for $30 \mathrm{~min}$ and dye $\mathbf{1 b}(1 \mu \mathrm{M})$ for another $20 \mathrm{~min}$.

Figure S18. Confocal laser fluorescence images of HeLa cells: (a-c) HeLa cells incubated with dye 1c (1 $\mu \mathrm{M})$ for 20 min; (d-f) HeLa cells treated with dexamethasone $(10 \mu \mathrm{M})$ for $30 \mathrm{~min}$ and dye 1c (1 $\mu \mathrm{M})$ for another $20 \mathrm{~min}$. S18

Figure S19. Confocal laser fluorescence images of HeLa cells: (a-c) HeLa cells incubated with dye 1e (1 $\mu$ M) for 20 min; $(d-f)$ HeLa cells treated with monensin $(10 \mu \mathrm{M})$ for $30 \mathrm{~min}$ and dye 1 e $(1 \mu \mathrm{M})$ for another $20 \mathrm{~min}$. S19

Figure S20. Confocal laser fluorescence images of HeLa cells: (a-c) HeLa cells incubated with dye 1f (1 $\mu$ M) for 20 min; (d-f) HeLa cells treated with monensin $(10 \mu \mathrm{M})$ for $30 \mathrm{~min}$ and dye $1 f(1 \mu \mathrm{M})$ for another $20 \mathrm{~min}$ S19

Figure S21. ${ }^{1} \mathrm{H}$ NMR of dye 1 a. S2O

Figure S22. ${ }^{1} \mathrm{H} N M R$ of dye $\mathbf{1 b}$ S20

Figure S23. ${ }^{1} \mathrm{H} N M R$ of dye $1 \mathrm{c}$. S21

Figure S24. ${ }^{1} \mathrm{H}$ NMR of dye $1 \mathrm{~d}$. 21

Figure S25. ${ }^{1} \mathrm{H} N \mathrm{NR}$ of dye 1 e. S22

Figure S26. ${ }^{1} \mathrm{H} N M R$ of dye $\mathbf{1 f}$. $S 22$ 


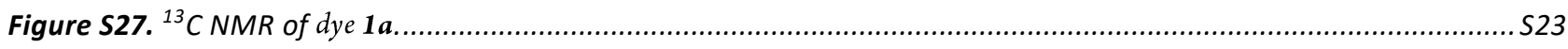

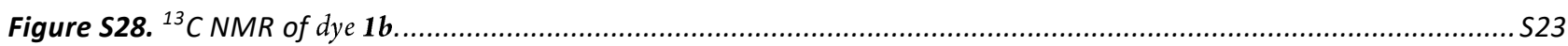

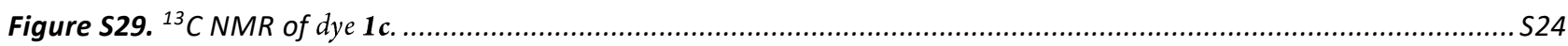

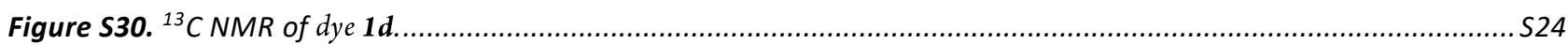

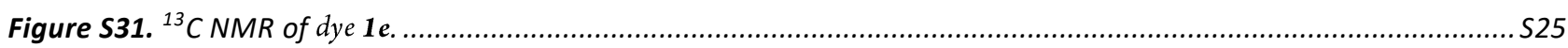

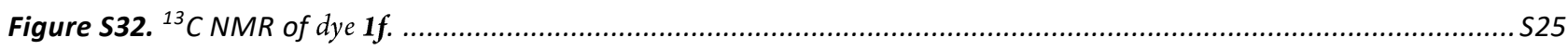

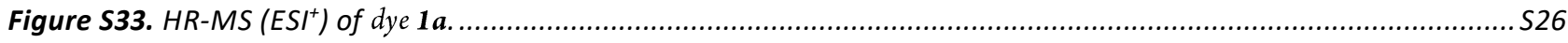

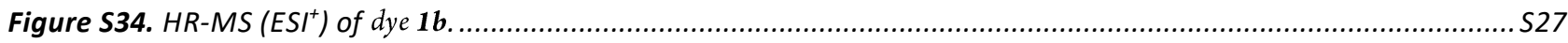

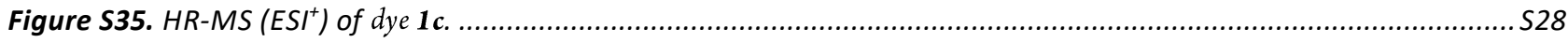

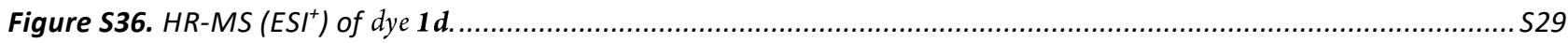

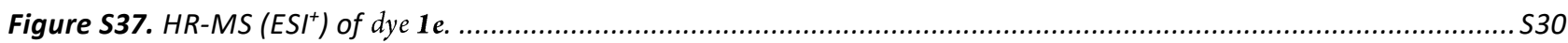

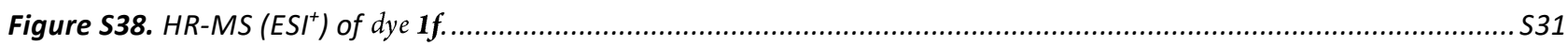

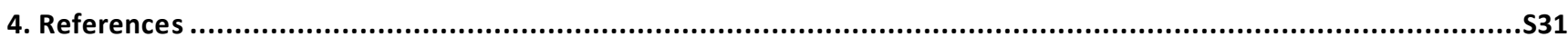




\section{Experimental Section}

\subsection{Materials and Apparatus}

Unless otherwise noted, all chemicals and solvents were achieved from Sigma-Aldrich. Compound 2 was synthesized by the published literature. ${ }^{1}$ Experimental materials used for the synthesis were analytically pure, and the solvents performed in the spectral assays were spectroscopically pure. All materials were used directly without further purification.

An X-4 microscope electron thermal apparatus was used to measure all melting points. ${ }^{1} \mathrm{H}$ NMR (400 $\mathrm{MHz}$ ) and ${ }^{13} \mathrm{C}$ NMR (600 MHz) spectra were measured on Bruker spectrometers. HR-MS date (ESI source) were recorded with a Finnigan MAT95 mass spectrometer. Fluorescence measurements were recorded on a Shimadzu RF-5301PC spectrofluorometer in $1 \mathrm{~cm} \times 1 \mathrm{~cm}$ quartz cells, and absorption spectra were taken on a Shimadzu UV-1800 spectrometer with $1 \mathrm{~cm} \times 1 \mathrm{~cm}$ quartz cells. The light source used for measure the transient absorption spectra were an optical parametric amplifier (OPA, Light Conversion ORPHEUS, $190 \mathrm{fs}, 20 \mathrm{~Hz}$ ), and pumped through mode-locked $\mathrm{Yb}: \mathrm{KGW}$-based fiber laser. The infrared spectra were obtained by Bruker VERTEX70 IR spectrometer. The cell fluorescence imaging pictures were captured by a laser confocal fluorescence microscopy.

\subsection{Synthesis}

\section{General procedure for the synthesis of dyes (1a-f)}

Dyes 1a-f were synthesized according to the previous method with some modification. ${ }^{2}$ Compound $2(0.5$

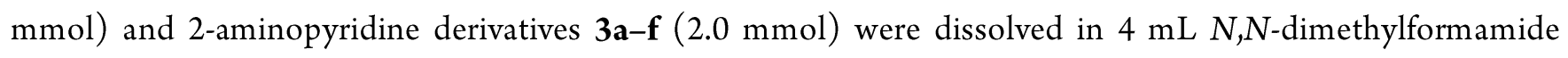

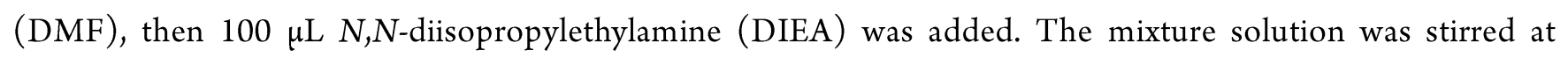
different temperatures $\left(\mathbf{1 a - b}\right.$ for $130^{\circ} \mathrm{C}$; $\mathbf{1 d}$ for $135^{\circ} \mathrm{C}$; $\mathbf{1 c}$ and $\mathbf{1 e - f}$ for $120^{\circ} \mathrm{C}$,) for different hours $(\mathbf{1 a - c}$ and 1e-f for $2 \mathrm{~h}, \mathbf{1 d}$ for $5 \mathrm{~h}$ ). After the reaction was completed, the mixture was poured into the stirring ether to form a large amount of solid. The crude products were purified by silica gel column chromatography using $\mathrm{CH}_{2} \mathrm{Cl}_{2} / \mathrm{MeOH}(25: 1, \mathrm{v} / \mathrm{v})$ as eluent to give pure products $1 \mathbf{a}-\mathbf{f}$ with yields of $42-70 \%$.

2-(2-(4-Bromo-8,9-dihydro-7H-pyrido[1,2-a]quinazolin-10-yl)vinyl)-1,1-dimethyl-3-propyl-1Hbenzo[e]indol-3-ium iodide (1a). Dark green solid (136.8 mg, yield 42\%), mp 204.1-204.4 ${ }^{\circ} \mathrm{C}$. IR $v$ (ATR, $\mathrm{cm}^{-}$ $\left.{ }^{1}\right): 1534,1365,1283,1202,1148,1111,1032,1005,938,917,903,891,822,675 .{ }^{1} \mathrm{H}$ NMR (400 MHz, DMSO$\left.d_{6}\right): \delta(\mathrm{ppm}) 9.02(\mathrm{~d}, J=6.4 \mathrm{~Hz}, 1 \mathrm{H}, \operatorname{Ar}-H), 8.70(\mathrm{~s}, 1 \mathrm{H}, \mathrm{Ar}-H), 8.60(\mathrm{~d}, J=7.3 \mathrm{~Hz}, 1 \mathrm{H}, \operatorname{Ar}-H), 8.17(\mathrm{~d}, J=8.5$ $\mathrm{Hz}, 1 \mathrm{H}, \mathrm{Ar}-H), 8.02(\mathrm{~m}, 2 \mathrm{H}, 2 \times \mathrm{Ar}-H), 7.87(\mathrm{~d}, J=13.2 \mathrm{~Hz}, 1 \mathrm{H}, \mathrm{CH}), 7.67(\mathrm{~d}, J=8.8 \mathrm{~Hz}, 1 \mathrm{H}, \mathrm{Ar}-H), 7.58(\mathrm{t}, J$ $=7.3 \mathrm{~Hz}, 1 \mathrm{H}, \operatorname{Ar}-H), 7.49(\mathrm{t}, J=7.2 \mathrm{~Hz}, 1 \mathrm{H}, \operatorname{Ar}-H), 7.44(\mathrm{t}, J=7.6 \mathrm{~Hz}, 1 \mathrm{H}, \operatorname{Ar}-H), 5.98(\mathrm{~d}, J=13.2 \mathrm{~Hz}, 1 \mathrm{H}$, 
$\mathrm{CH}), 4.18\left(\mathrm{t}, 2 \mathrm{H}, J=8.0 \mathrm{~Hz}, \mathrm{CH}_{2}\right), 2.86\left(\mathrm{~m}, 4 \mathrm{H}, 2 \times \mathrm{CH}_{2}\right), 1.96\left(\mathrm{t}, 2 \mathrm{H}, J=6.9 \mathrm{~Hz}, \mathrm{CH}_{2}\right), 1.85(\mathrm{q}, 2 \mathrm{H}, J=7.5 \mathrm{~Hz}$, $\left.\mathrm{CH}_{2}\right), 1.75\left(\mathrm{~s}, 6 \mathrm{H}, 2 \times \mathrm{CH}_{3}\right), 1.00\left(\mathrm{t}, J=6.8 \mathrm{~Hz}, 3 \mathrm{H}, \mathrm{CH}_{3}\right) \cdot{ }^{13} \mathrm{C}$ NMR $\left(151 \mathrm{MHz}, \mathrm{DMSO}-d_{6}\right): \delta(\mathrm{ppm}) 153.6$, $152.1,148.4,141.2$, 140.8, 139.3, 134.9, 131.0, 130.4, 130.2, 128.7, 128.2, 127.8, 124.4, 122.3, 121.5, 118.6, 115.7, 115.6, 111.6, 94.4, 65.3, 50.0, 28.9, 27.8, 27. 2, 20.9, 20.5, 15.6, 11.6. HRMS (ESI+): Calcd for $\mathrm{C}_{31} \mathrm{H}_{31} \mathrm{BrN}_{3}{ }^{+}\left[\mathrm{M}-\mathrm{I}^{-}\right]^{+}, 524.1696$; found, 524.1704.

2-(2-(3-Chloro-8,9-dihydro-7H-pyrido[1,2-a]quinazolin-10-yl)vinyl)-1,1-dimethyl-3-propyl-1Hbenzo[e]indol-3-ium iodide (1b). Dark green solid (128.3 mg, yield 45\%), mp > 250.0 ${ }^{\circ} \mathrm{C}$. IR $v\left(\mathrm{ATR}, \mathrm{cm}^{-1}\right): 1548$, 1386, 1371, 1288, 1269, 1231, 1201, 1188, 1166, 1148, 1113, 1083, 943, 733, 673. ' H NMR (400 MHz, DMSO$\left.d_{6}\right) \delta(\mathrm{ppm}) 9.04(\mathrm{~d}, J=6.4 \mathrm{~Hz}, 1 \mathrm{H}, \mathrm{Ar}-H), 8.69$ (s, 1H, Ar-H), 8.35 (s, 1H, Ar-H), 8.20 (d, J = 8.3 Hz, 1H, Ar$H), 8.00(\mathrm{~d}, J=7.1 \mathrm{~Hz}, 2 \mathrm{H}, 2 \times \mathrm{Ar}-H), 7.85(\mathrm{~d}, J=13.0 \mathrm{~Hz}, 1 \mathrm{H}, \mathrm{CH}), 7.74(\mathrm{~d}, J=7.1 \mathrm{~Hz}, 1 \mathrm{H}, \operatorname{Ar}-H), 7.65(\mathrm{~d}, J=$ 8.7 Hz, 1H, Ar-H), $7.57(\mathrm{t}, J=7.2 \mathrm{~Hz}, 1 \mathrm{H}, \mathrm{Ar}-H), 7.43(\mathrm{t}, J=7.3 \mathrm{~Hz}, 1 \mathrm{H}, \mathrm{Ar}-H), 5.94(\mathrm{~d}, J=13.0 \mathrm{~Hz}, 1 \mathrm{H}, \mathrm{CH})$, $4.16\left(\mathrm{t}, 2 \mathrm{H}, J=5.6 \mathrm{~Hz}, \mathrm{CH}_{2}\right), 2.84\left(\mathrm{t}, 4 \mathrm{H}, J=6.6 \mathrm{~Hz}, 2 \times \mathrm{CH}_{2}\right), 1.93\left(\mathrm{t}, 2 \mathrm{H}, J=5.8 \mathrm{~Hz}, \mathrm{CH}_{2}\right), 1.83(\mathrm{t}, 2 \mathrm{H}, J=7.6$ $\left.\mathrm{Hz}, \mathrm{CH}_{2}\right), 1.77\left(\mathrm{~s}, 6 \mathrm{H}, 2 \times \mathrm{CH}_{3}\right), 1.00\left(\mathrm{t}, J=7.2 \mathrm{~Hz}, 3 \mathrm{H}, \mathrm{CH}_{3}\right) \cdot{ }^{13} \mathrm{C}$ NMR $\left(151 \mathrm{MHz}, \mathrm{DMSO}-d_{6}\right): \delta(\mathrm{ppm})$ 169.9 , 153.3, 152.6, 151.1, 143.6, 140.9, 138.3, 136.0, 132.0, 130.9, 130.3, 130.2, 128.2, 128.1, 127.8, 126.3, 124.2, 122.3, 120.2, 115.1, 111.5, 94.0, 49.8, 44.5, 28.9, 27.7, 27.2, 20.9, 20.4, 11.6. HRMS (ESI ${ }^{+}$: Calcd for $\mathrm{C}_{31} \mathrm{H}_{31} \mathrm{ClN}_{3}{ }^{+}\left[\mathrm{M}-\mathrm{I}^{-}\right]^{+}$, 480.2201; found, 480.2224 .

2-(2-(4-(Hydroxymethyl)-8,9-dihydro-7H-pyrido[1,2-a]quinazolin-10-yl)vinyl)-1,1-dimethyl-3-propyl-1Hbenzo[e]indol-3-ium iodide (1c). Black solid (196.1 mg, yield 65\%), mp > 250.0 ${ }^{\circ} \mathrm{C}$. IR $v\left(\mathrm{ATR}, \mathrm{cm}^{-1}\right): 3295$, 1548, 1442, 1361, 1283, 1229, 1192, 1117, 1051, 1010, 984, 939, 927, 882, 678. ' H NMR (400 MHz, DMSO$\left.d_{6}\right): \delta(\mathrm{ppm}) 9.05(\mathrm{~d}, J=4.8 \mathrm{~Hz}, 1 \mathrm{H}, \mathrm{Ar}-H), 8.74(\mathrm{~s}, 1 \mathrm{H}, \mathrm{Ar}-H), 8.25(\mathrm{~d}, J=6.8 \mathrm{~Hz}, 1 \mathrm{H}, \mathrm{Ar}-H), 8.14(\mathrm{~d}, J=9.5$ $\mathrm{Hz}, 1 \mathrm{H}, \mathrm{Ar}-H), 7.99$ (d, J= 8.2 Hz, 2H, $2 \times \mathrm{Ar}-H), 7.84(\mathrm{~d}, J=13.0 \mathrm{~Hz}, 1 \mathrm{H}, \mathrm{CH}), 7.74(\mathrm{t}, J=7.0 \mathrm{~Hz}, 1 \mathrm{H}, \operatorname{Ar}-H)$, $7.63(\mathrm{~d}, J=8.8 \mathrm{~Hz}, 1 \mathrm{H}, \mathrm{Ar}-H), 7.56(\mathrm{t}, J=7.3 \mathrm{~Hz}, 1 \mathrm{H}, \mathrm{Ar}-H), 7.41(\mathrm{t}, J=7.5 \mathrm{~Hz}, 1 \mathrm{H}, \mathrm{Ar}-H), 5.92(\mathrm{~d}, J=12.7 \mathrm{~Hz}$, $1 \mathrm{H}, \mathrm{CH}), 5.00(\mathrm{~s}, 1 \mathrm{H}, \mathrm{O}-\mathrm{H}), 4.14\left(\mathrm{~s}, 2 \mathrm{H}, \mathrm{CH}_{2}\right), 2.87\left(\mathrm{t}, 4 \mathrm{H}, J=5.5 \mathrm{~Hz}, 2 \times \mathrm{CH}_{2}\right), 1.96\left(\mathrm{t}, 2 \mathrm{H}, J=8.2 \mathrm{~Hz}, \mathrm{CH}_{2}\right)$, $1.83\left(\mathrm{t}, 2 \mathrm{H}, J=7.1 \mathrm{~Hz}, \mathrm{CH}_{2}\right), 1.76\left(\mathrm{~s}, 6 \mathrm{H}, 2 \times \mathrm{CH}_{3}\right), 1.00\left(\mathrm{t}, J=8.7 \mathrm{~Hz}, 3 \mathrm{H}, \mathrm{CH}_{3}\right) .{ }^{13} \mathrm{C} \mathrm{NMR}(151 \mathrm{MHz}$ DMSO- $\left.d_{6}\right): \delta(\mathrm{ppm}) 168.9,152.7,152.7,148.0,141.0,139.8,137.6,133.9,132.8,131.6,130.8,130.3,130.2$, 128.3, 128.2, 127.7, 124.1, 122.1, 119.4, 115.2, 111.4, 93.4, 59.2, 49.5, 44.3, 29.0, 27.6, 27.2, 21.1, 20.4, 11.7. HRMS (ESI ${ }^{+}$): Calcd for $\mathrm{C}_{32} \mathrm{H}_{34} \mathrm{~N}_{3} \mathrm{O}^{+}\left[\mathrm{M}-\mathrm{I}^{-}\right]^{+}, 476.2696$; found, 476.2726.

2-(2-(4-Amino-8,9-dihydro-7H-pyrido[1,2-a]quinazolin-10-yl)vinyl)-1,1-dimethyl-3-propyl-1Hbenzo[e]indol-3-ium iodide(1d). Black solid (173.6 mg, yield 59\%), $\mathrm{mp}>250.0^{\circ} \mathrm{C}$. IR $v\left(\mathrm{ATR}, \mathrm{cm}^{-1}\right): 3458,1555$, $1537,1518,1436,1353,1291,1266,1234,1141,1104,945,802,756,633 .{ }^{1} \mathrm{H}$ NMR $\left(400 \mathrm{MHz}, \mathrm{DMSO}-d_{6}\right): \delta$ 
$(\mathrm{ppm}) 8.85(\mathrm{~d}, J=13.7 \mathrm{~Hz}, 1 \mathrm{H}, \mathrm{CH}), 8.72(\mathrm{~s}, 1 \mathrm{H}, \mathrm{Ar}-H), 8.23(\mathrm{~d}, J=8.4 \mathrm{~Hz}, 1 \mathrm{H}, \mathrm{Ar}-H), 7.99(\mathrm{~d}, J=8.6 \mathrm{~Hz}, 1 \mathrm{H}$, $\operatorname{Ar}-H), 7.92(\mathrm{~d}, J=6.4 \mathrm{~Hz}, 1 \mathrm{H}, \mathrm{Ar}-H), 7.61(\mathrm{~m}, 2 \mathrm{H}, 2 \times \operatorname{Ar}-H), 7.42(\mathrm{t}, J=7.5 \mathrm{~Hz}, 1 \mathrm{H}, \mathrm{Ar}-H), 7.34(\mathrm{t}, J=7.2 \mathrm{~Hz}$ $1 \mathrm{H}, \operatorname{Ar}-H), 7.26(\mathrm{t}, J=7.6 \mathrm{~Hz}, 1 \mathrm{H}, \mathrm{Ar}-H), 6.29\left(\mathrm{~s}, 1 \mathrm{H}, \mathrm{NH} \mathrm{H}_{2}\right), 5.97(\mathrm{~d}, J=13.8 \mathrm{~Hz}, 1 \mathrm{H}, \mathrm{CH}), 4.11(\mathrm{t}, 2 \mathrm{H}, J=6.6$ $\left.\mathrm{Hz}, \mathrm{CH}_{2}\right), 2.86\left(\mathrm{t}, 2 \mathrm{H}, J=5.4 \mathrm{~Hz}, \mathrm{CH}_{2}\right), 2.76\left(\mathrm{t}, 2 \mathrm{H}, J=6.5 \mathrm{~Hz}, \mathrm{CH}_{2}\right), 1.96\left(\mathrm{~s}, 6 \mathrm{H}, 2 \times \mathrm{CH}_{3}\right), 1.90(\mathrm{t}, 2 \mathrm{H}, J=5.6$ $\left.\mathrm{Hz}, \mathrm{CH}_{2}\right), 1.80\left(\mathrm{q}, 2 \mathrm{H}, J=7.3 \mathrm{~Hz}, \mathrm{CH}_{2}\right), 1.00\left(\mathrm{t}, J=7.1 \mathrm{~Hz}, 3 \mathrm{H}, \mathrm{CH}_{3}\right) .{ }^{13} \mathrm{C}$ NMR $\left(151 \mathrm{MHz}, \mathrm{DMSO}-d_{6}\right): \delta$ (ppm) 169.7, 158.8, 141.6, 141.1, 138.9, 137.8, 136.7, 131.1, 130.8, 130.3, 130.3, 128.3, 127.7, 127.4, 124.0, 122.2, 122.1, 120.1, 119.4, 114.2, 111.4, 95.1, 49.6, 44.2, 28.6, 26.9, 24.7, 20.4, 20.2, 11.6. HRMS (ESI $)$ : Calcd for $\mathrm{C}_{31} \mathrm{H}_{33} \mathrm{~N}_{4}^{+}\left[\mathrm{M}-\mathrm{I}^{-}\right]^{+}$, 461.2700; found, 461.2715.

1,1-Dimethyl-2-(2-(4-methyl-8,9-dihydro-7H-pyrido[1,2-a]quinazolin-10-yl)vinyl)-3-propyl-1Hbenzo[e]indol-3-ium iodide (1e). Black solid (205.5 mg, yield 70\%), mp 223.7-223.9 ${ }^{\circ} \mathrm{C}$. IR $v\left(\mathrm{ATR}, \mathrm{cm}^{-1}\right): 1542$, 1502, 1431, 1366, 1289, 1230, 1192, 1139, 1086, 1010, 944, 884, 801, 675. ${ }^{1} \mathrm{H}$ NMR (400 MHz, DMSO- $\left.d_{6}\right): \delta$ (ppm) $9.03(\mathrm{~d}, J=5.0 \mathrm{~Hz}, 1 \mathrm{H}, \mathrm{Ar}-H), 8.79(\mathrm{~s}, 1 \mathrm{H}, \mathrm{Ar}-H), 8.17(\mathrm{~m}, 2 \mathrm{H}, 2 \times \operatorname{Ar}-H), 7.98(\mathrm{~m}, 2 \mathrm{H}, 2 \times \operatorname{Ar}-H), 7.83$ $(\mathrm{d}, J=12.9 \mathrm{~Hz}, 1 \mathrm{H}, \mathrm{CH}), 7.65(\mathrm{~m}, 2 \mathrm{H}, 2 \times \mathrm{Ar}-H), 7.56(\mathrm{t}, J=7.3 \mathrm{~Hz}, 1 \mathrm{H}, \mathrm{Ar}-H), 7.40(\mathrm{t}, J=7.4 \mathrm{~Hz}, 1 \mathrm{H}, \operatorname{Ar}-H)$, $5.90(\mathrm{~d}, J=12.8 \mathrm{~Hz}, 1 \mathrm{H}, \mathrm{CH}), 4.13\left(\mathrm{t}, 2 \mathrm{H}, J=7.0 \mathrm{~Hz}, \mathrm{CH}_{2}\right), 2.87\left(\mathrm{t}, 2 \mathrm{H}, J=5.7 \mathrm{~Hz}, \mathrm{CH}_{2}\right), 2.70\left(\mathrm{~s}, 3 \mathrm{H}, \mathrm{CH}_{3}\right)$, $1.96\left(\mathrm{t}, 2 \mathrm{H}, J=6.3 \mathrm{~Hz}, \mathrm{CH}_{2}\right), 1.83\left(\mathrm{q}, 2 \mathrm{H}, J=6.8 \mathrm{~Hz}, \mathrm{CH}_{2}\right), 1.75\left(\mathrm{~s}, 6 \mathrm{H}, 2 \times \mathrm{CH}_{3}\right), 1.01\left(\mathrm{t}, J=7.1 \mathrm{~Hz}, 3 \mathrm{H}, \mathrm{CH}_{3}\right)$. ${ }^{13} \mathrm{C}$ NMR (151 MHz, DMSO-d $): \delta(\mathrm{ppm}) 168.7$ 153.7, 152.4, 150.8, 141.1, 139.0, 137.0, 134.7, 131.5, 130.7, 130.3, 130.2, 128.3, 128.1, 128.0, 127.7, 124.0, 122.0, 120.1, 114.8, 111.4, 93.1, 49.5, 44.2, 40.5, 29.0, 27.6, 27.2, 21.1, 20.3, 11.7. HRMS (ESI ${ }^{+}$): Calcd for $\mathrm{C}_{32} \mathrm{H}_{32} \mathrm{~N}_{3}{ }^{+}\left[\mathrm{M}-\mathrm{I}^{-}\right]^{+}, 460.2747$; found, 460.2761 .

2-(2-(4-Methoxy-8,9-dihydro-7H-pyrido[1,2-a]quinazolin-10-yl)vinyl)-1,1-dimethyl-3-propyl-1Hbenzo[e]indol-3-ium iodide (1f). Black solid (205.1 mg, yield 68\%), mp 175.2.0-175.5 ${ }^{\circ} \mathrm{C}$. IR $v\left(\mathrm{ATR}, \mathrm{cm}^{-1}\right)$ : 1550, 1507, 1431, 1362, 1302, 1225, 1189, 1130, 1079, 1031, 986, 955, 892, 737, 682. ${ }^{\mathrm{H}} \mathrm{NMR}(400 \mathrm{MHz}$, $\left.\mathrm{CDCl}_{3}\right): \delta(\mathrm{ppm}) 8.75(\mathrm{~d}, J=6.8 \mathrm{~Hz}, 1 \mathrm{H}, \mathrm{Ar}-H), 8.42(\mathrm{~s}, 1 \mathrm{H}, \mathrm{Ar}-H), 8.08(\mathrm{~d}, J=8.5 \mathrm{~Hz}, 1 \mathrm{H}, \mathrm{Ar}-H), 7.90(\mathrm{~m}$, $4 \mathrm{H}, 4 \times \operatorname{Ar}-H), 7.75(\mathrm{~d}, J=7.8 \mathrm{~Hz}, 1 \mathrm{H}, \mathrm{Ar}-H), 7.57(\mathrm{t}, J=7.3 \mathrm{~Hz}, 1 \mathrm{H}, \operatorname{Ar}-H), 7.42(\mathrm{t}, J=7.5 \mathrm{~Hz}, 1 \mathrm{H}, \operatorname{Ar}-H), 7.31$ $(\mathrm{d}, J=9.3 \mathrm{~Hz}, 1 \mathrm{H}, \mathrm{Ar}-H), 5.85(\mathrm{~d}, J=13.2 \mathrm{~Hz}, 1 \mathrm{H}, \mathrm{CH}), 4.23\left(\mathrm{~s}, 3 \mathrm{H}, \mathrm{CH}_{3}\right), 4.08$ (t, 2H, J=6.9 Hz, $\left.\mathrm{CH}_{2}\right), 2.91$ $\left(\mathrm{t}, 2 \mathrm{H}, J=7.1 \mathrm{~Hz}, \mathrm{CH}_{2}\right), 2.87\left(\mathrm{t}, 2 \mathrm{H}, J=7.1 \mathrm{~Hz}, \mathrm{CH}_{2}\right), 2.12\left(\mathrm{t}, 2 \mathrm{H}, J=7.1 \mathrm{~Hz}, \mathrm{CH}_{2}\right), 1.96\left(\mathrm{~s}, 6 \mathrm{H}, 2 \times \mathrm{CH}_{3}\right), 1.83$ $\left(\mathrm{q}, 2 \mathrm{H}, J=7.0 \mathrm{~Hz}, \mathrm{CH}_{2}\right), 1.10\left(\mathrm{t}, 2 \mathrm{H}, J=7.0 \mathrm{~Hz}, \mathrm{CH}_{2}\right) .{ }^{13} \mathrm{C} \mathrm{NMR}\left(151 \mathrm{MHz}, \mathrm{DMSO}-d_{6}\right): \delta(\mathrm{ppm})$ 168.8, 153.0, 152.6, 152.0, 144.8, 141.1, 137.5, 131.5, 130.8, 130.3, 130.2, 128.9, 128.3, 127.7, 126.3, 124.0, 122.1, 119.4, 115.1, 114.6, 111.4, 93.3, 65.3, 57.7, 29.0, 27.6, 27.2, 21.1, 20.3, 15.6, 11.7. HRMS (ESI ): Calcd for $\mathrm{C}_{32} \mathrm{H}_{33} \mathrm{~N}_{3}{ }^{+}$ $\left[\mathrm{M}-\mathrm{I}^{-}\right]^{+}, 476.2696$; found, 476.2724 . 


\subsection{Optical test of the solutions}

The assay solutions $(10 \mu \mathrm{M})$ of dyes 1a-f were prepared from $1 \mathrm{mM}$ stock solutions in DMSO unless otherwise noted. The solutions with different viscosities were obtained by adding $100 \mu \mathrm{L}$ stock solution to the solvent mixture (PBS buffer $(\mathrm{pH}=7.4)$ and glycerol in different proportions) in a $10 \mathrm{~mL}$ volumetric flask. The solutions were sonicated for $8 \mathrm{~min}$ to eliminate air bubbles and kept at $25{ }^{\circ} \mathrm{C}$ for $1 \mathrm{~h}$, then the spectral experiments were performed. Stock solutions $(1 \mathrm{mM})$ of various interfering substances (including Cys, GSH, $\left.\mathrm{Hcy}, \mathrm{Mg}^{2+}, \mathrm{Na}^{+}, \mathrm{Fe}^{3+}, \mathrm{F}^{-}, \mathrm{Cl}^{-}, \mathrm{HSO}_{3}{ }^{-}, \mathrm{S}^{2-}, \mathrm{S}_{2} \mathrm{O}_{3}{ }^{2-}, \mathrm{CO}_{3}{ }^{2-}, \mathrm{ClO}^{-}, \mathrm{H}_{2} \mathrm{O}_{2}\right)$ were prepared in twice distilled water. In the selectivity assay, the test solutions were obtained by mixing $100 \mu \mathrm{L}$ stock solution of dyes $\mathbf{1 a - f}, 1 \mathrm{~mL}$ stock solutions of the corresponding interfering substances and PBS buffer $(\mathrm{pH}=7.4)$ to afford $10 \mathrm{~mL}$ total volume. Britton-Robinson (B-R) buffer solution $(40 \mathrm{mM})$ was used in the $\mathrm{pH}$ experiments. Dyes 1a-f solutions with different $\mathrm{pH}$ values were prepared by placing $100 \mu \mathrm{L}$ stock solution and $5 \mathrm{~mL}$ glycerol to a $10 \mathrm{~mL}$ volumetric flask, and adding B-R buffer solutions with different $\mathrm{pH}$ values to gain the final concentration of $10 \mathrm{~mL}$. Dyes 1a-f in solvents with different polarities were prepared by adding $100 \mu \mathrm{L}$ stock solution of dyes 1a-f and corresponding solvents (toluene (PhMe), ethyl acetate, tetrahydrofuran, 1,4-dioxane, acetone, ethanol (EtOH), methanol $(\mathrm{MeOH})$, dimethyl sulfoxide and $\left.\mathrm{H}_{2} \mathrm{O}\right)$ to give a total volume of $10 \mathrm{~mL}$. In all fluorescence measurements, the excitation wavelength was selected at $605 \mathrm{~nm}$, the slit widths of fluorescence spectra for dyes 1a-f were different (dyes 1a-b: $3 \mathrm{~nm} / 5 \mathrm{~nm}$; dyes 1 c and 1e-f: $3 \mathrm{~nm} / 3 \mathrm{~nm}$; dye $\mathbf{1 d}: 3 \mathrm{~nm} / 1.5 \mathrm{~nm}$ ). The stock solution for transient absorption assays was $20 \mathrm{mM}$, the test solutions were prepared by mixing $100 \mu \mathrm{L}$ stock solution of dyes $\mathbf{1 a - f}$ and PBS buffer or glycerol to afford $10 \mathrm{~mL}$ total volume.

All the relative fluorescence quantum yields of dyes $\mathbf{1 a - f}$ were evaluated by the following equation:

$$
\Phi_{\mathrm{x}} / \Phi_{\mathrm{st}}=\left[\mathrm{A}_{\mathrm{st}} / \mathrm{A}_{\mathrm{x}}\right]\left[\mathrm{n}_{\mathrm{x}}^{2} / \mathrm{n}_{\mathrm{st}}{ }^{2}\right]\left[\mathrm{D}_{\mathrm{x}} / \mathrm{D}_{\mathrm{st}}\right]
$$

where st: standard, x: sample, $\Phi:$ quantum yield, A: absorbance at the excitation wavelength, D: area under the fluorescence spectra on an energy scale, n: the refractive index of the mixed solution; Oxazine $1(\Phi=0.14$ in ethanol) was used as the standard. ${ }^{3}$

\subsection{Cell culture and imaging}

HeLa cells were cultivated at $37^{\circ} \mathrm{C}$ in Roswell Park Memorial Institute culture medium (RPMI-1640) supplemented with $10 \%$ calf serum, $1 \%$ penicillin, and L-glutamine $\left(2.5 \times 10^{-4} \mathrm{M}\right)$, and were cultured in a $\mathrm{CO}_{2}$ incubator $\left(5 \% \mathrm{CO}_{2}\right)$. The cells were loaded onto a glass-bottomed coverslip and allowed to adhere for 2 days before dye loading. 
In the co-localization experiments, HeLa cells were incubated with commercial lysosomal or mitochondrial markers (100 nM) (LysoTracker Green DND-26 or MitoTracker Green FM) and dyes 1a-f (3 $\mu \mathrm{M})$ for $20 \mathrm{~min}$, then excess dyes $\mathbf{1 a - f}$ and commercial marker were removed by gently washing with PBS (1 mL) three times before being taken pictures. In the experiments for monitoring mitochondrial or lysosomal viscosity, HeLa cells were pre-treated with monensin or dexamethasone $(10 \mu \mathrm{M})$ for half an hour, and dyes $1 \mathbf{a}-\mathbf{f}(1 \mu \mathrm{M})$ were added and co-incubated for $20 \mathrm{~min}$. The images were captured after the cells were rinsed three times with PBS. The red channel images were acquired between $575 \mathrm{~nm}$ and $745 \mathrm{~nm}$ at $561 \mathrm{~nm}$ excitation, and the green channel images were collected between $505 \mathrm{~nm}$ and $565 \mathrm{~nm}$ at $488 \mathrm{~nm}$ excitation. 


\section{Figures}
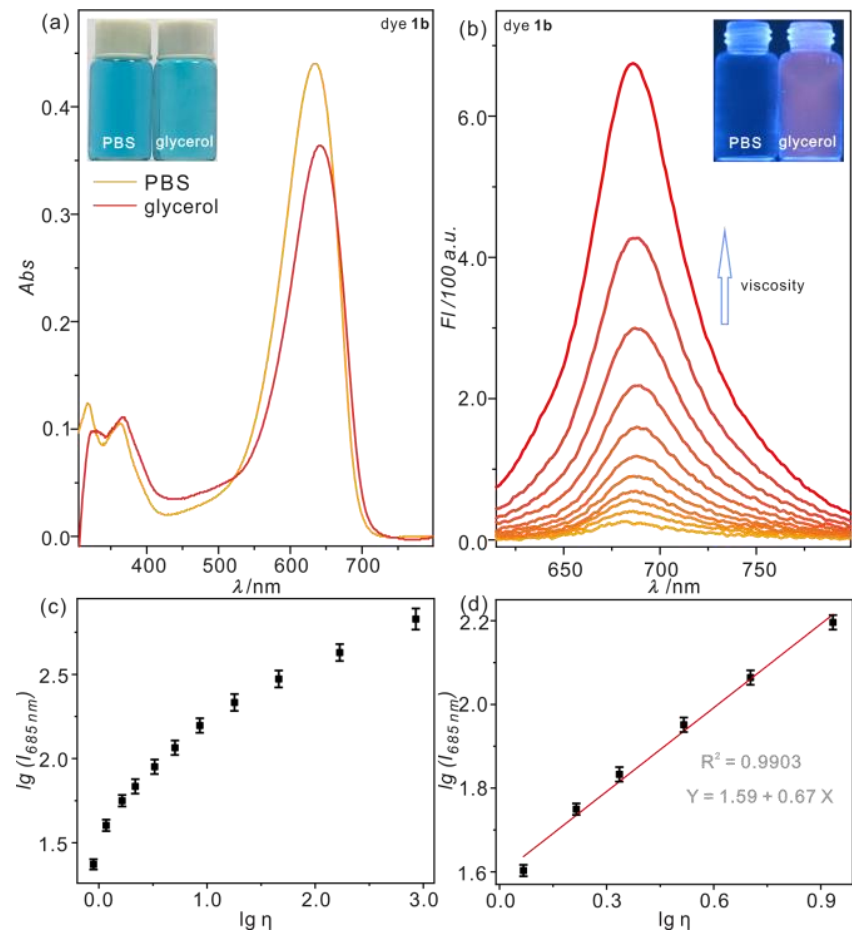

Figure S1. Optical spectra of dye $1 \mathbf{b}(10 \mu \mathrm{M})$ in different ratios of glycerol-PBS mixtures containing $1 \%$ DMSO (0.89 cP-856 cP): (a) absorption spectrum, insert: the color change of dye 1b in PBS and glycerol under daylight. (b) Fluorescence spectrum, insert photograph showed dye $\mathbf{1 b}$ in PBS and glycerol under a $365 \mathrm{~nm}$ lamp in darkroom, $\lambda_{\mathrm{ex}}=605 \mathrm{~nm}$, slit widths: $3 \mathrm{~nm} / 5 \mathrm{~nm}$. (c) Relationship between Ig (I $\left.685 \mathrm{~nm}\right)$ and Ig $\eta$; (d) linear relationship between $\lg \left(I_{685} \mathrm{~nm}\right)$ and $\lg \eta$, the data were shown as mean $\pm S D(n=3)$.
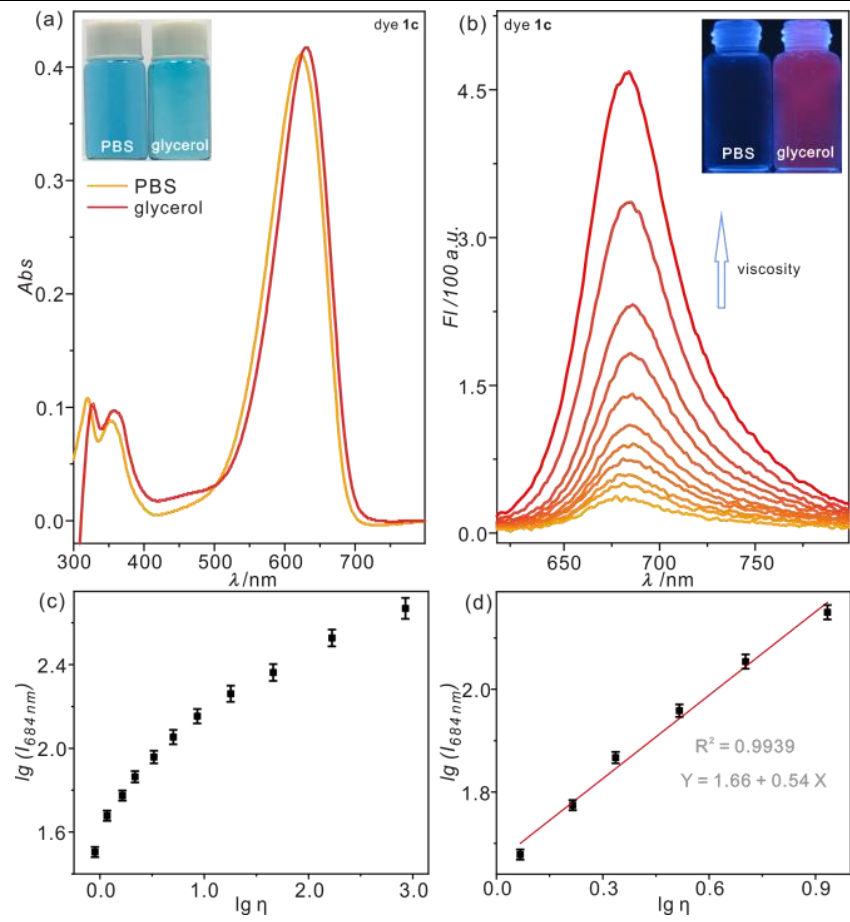

Figure S2. Optical spectra of dye 1c $(10 \mu \mathrm{M})$ in different ratios of glycerol-PBS mixtures containing $1 \%$ DMSO (0.89 cP-856 cP): (a) absorption spectrum, insert: the color change of dye 1c in PBS and glycerol under daylight. (b) Fluorescence spectrum, insert photograph showed dye 1c in PBS and glycerol under a $365 \mathrm{~nm}$ lamp in darkroom, $\lambda_{\mathrm{ex}}=605 \mathrm{~nm}$, slit widths: $3 \mathrm{~nm} / 3 \mathrm{~nm}$. (c) Relationship between Ig (I $\left.684 \mathrm{~nm}\right)$ and $\lg \eta$; (d) linear relationship between $\lg \left(I_{684} \mathrm{~nm}\right)$ and $\lg \eta$, the data were shown as mean $\pm S D(n=3)$. 

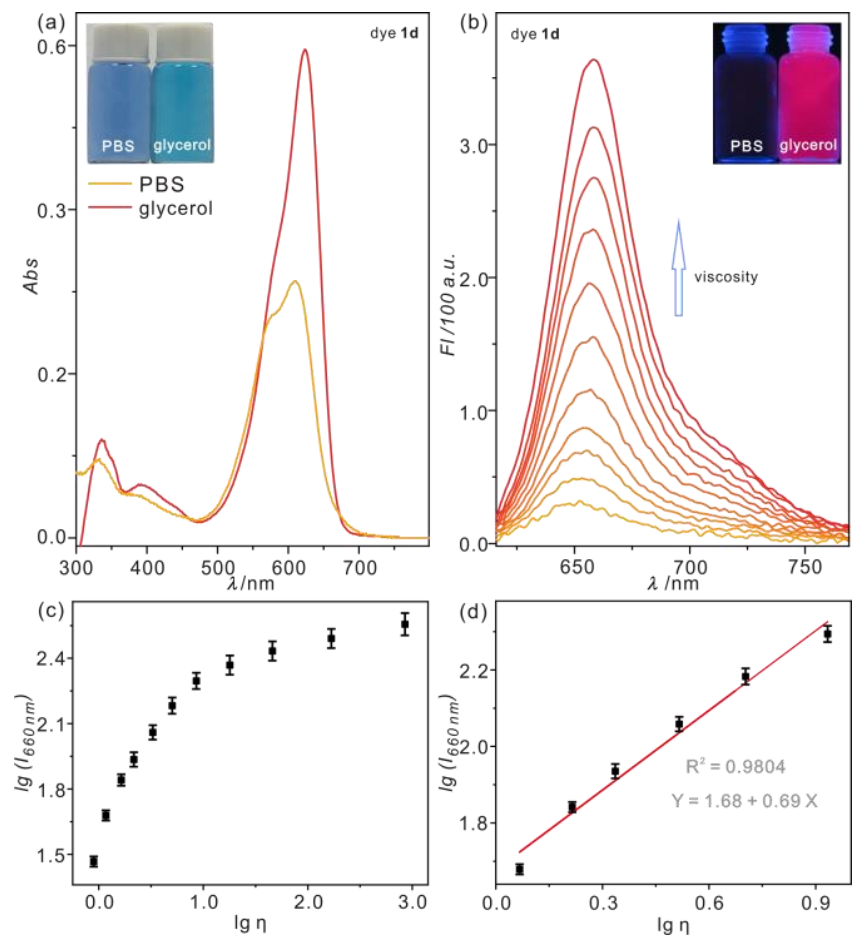

Figure S3. Optical spectra of dye 1d $(10 \mu \mathrm{M})$ in different ratios of glycerol-PBS mixtures containing $1 \%$ DMSO (0.89 cP-856 cP): (a) absorption spectrum, insert: the color change of dye 1d in PBS and glycerol under daylight. (b) Fluorescence spectrum, insert photograph showed dye 1d in PBS and glycerol under a $365 \mathrm{~nm}$ lamp in darkroom, $\lambda_{\mathrm{ex}}=605 \mathrm{~nm}$, slit widths: $3 \mathrm{~nm} / 1.5 \mathrm{~nm}$. (c) Relationship between lg $\left(\mathrm{I}_{660 \mathrm{~nm}}\right)$ and lg $\underline{\eta}$; (d) linear relationship between $\lg \left(I_{660} \mathrm{~nm}\right)$ and $\lg \eta$, the data were shown as mean $\pm \operatorname{SD}(n=3)$.
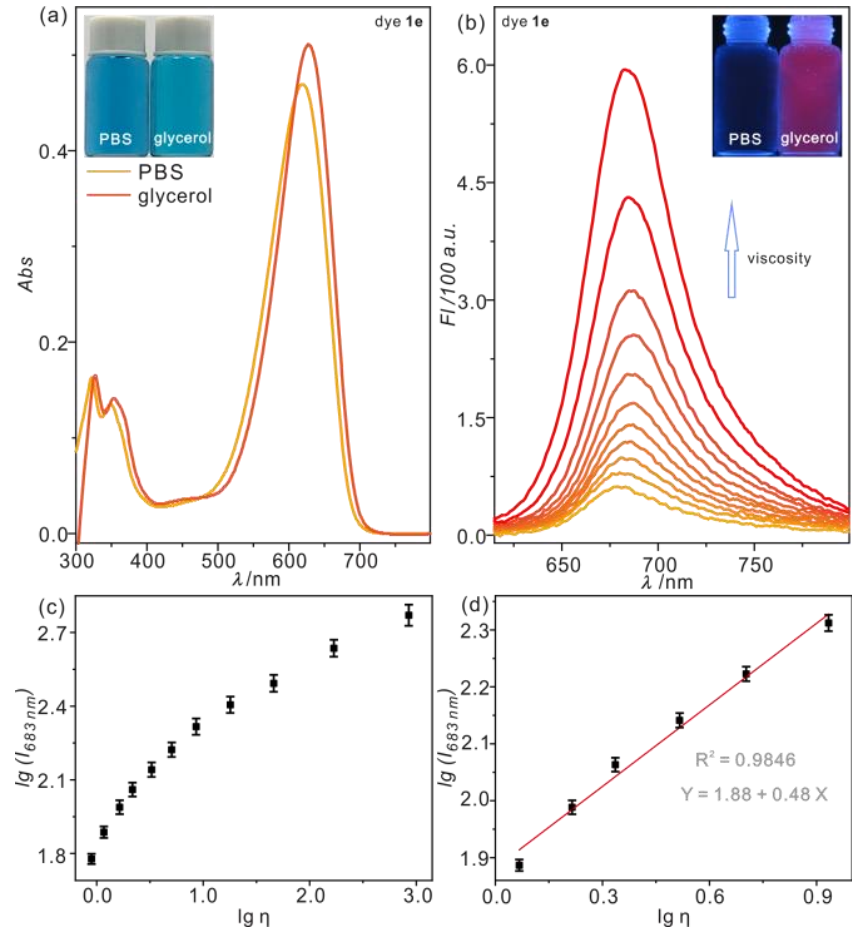

Figure S4. Optical spectra of dye 1 e $(10 \mu \mathrm{M})$ in different ratios of glycerol-PBS mixtures containing $1 \%$ DMSO (0.89 cP-856 cP): (a) absorption spectrum, insert: the color change of dye 1e in PBS and glycerol under daylight. (b) Fluorescence spectrum, insert photograph showed dye 1e in PBS and glycerol under a $365 \mathrm{~nm}$ lamp in darkroom, $\lambda_{\mathrm{ex}}=605 \mathrm{~nm}$, slit widths: $3 \mathrm{~nm} / 3 \mathrm{~nm}$. (c) Relationship between Ig (I $\left.683 \mathrm{~nm}\right)$ and lg $\eta$; (d) linear relationship between $\lg \left(I_{683} \mathrm{~nm}\right)$ and $\lg \eta$, the data were shown as mean $\pm S D(n=3)$. 

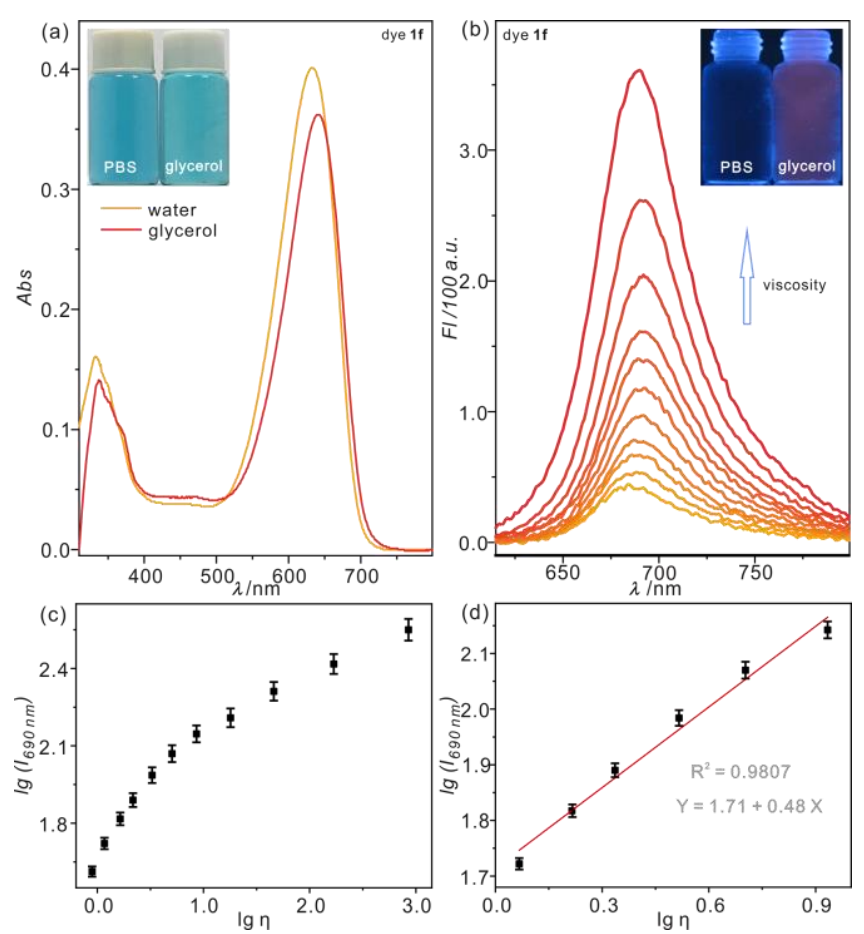

Figure S5. Optical spectra of dye 1f $(10 \mu \mathrm{M})$ in different ratios of glycerol-PBS mixtures containing $1 \%$ DMSO (0.89 cP-856 cP): (a) absorption spectrum, insert: the color change of dye 1f in PBS and glycerol under daylight. (b) fluorescence spectrum, insert photograph showed dye 1f in PBS and glycerol under a 365 $\mathrm{nm}$ lamp in darkroom, $\lambda_{\mathrm{ex}}=605 \mathrm{~nm}$, slit widths: $3 \mathrm{~nm} / 3 \mathrm{~nm}$. (c) Relationship between $\mathrm{lg}(\mathrm{I} 690 \mathrm{~nm})$ and $\mathrm{lg} \eta$; (d) linear relationship between $\lg \left(I_{690 \mathrm{~nm}}\right)$ and $\lg \eta$, the data were shown as mean $\pm \operatorname{SD}(n=3)$. 


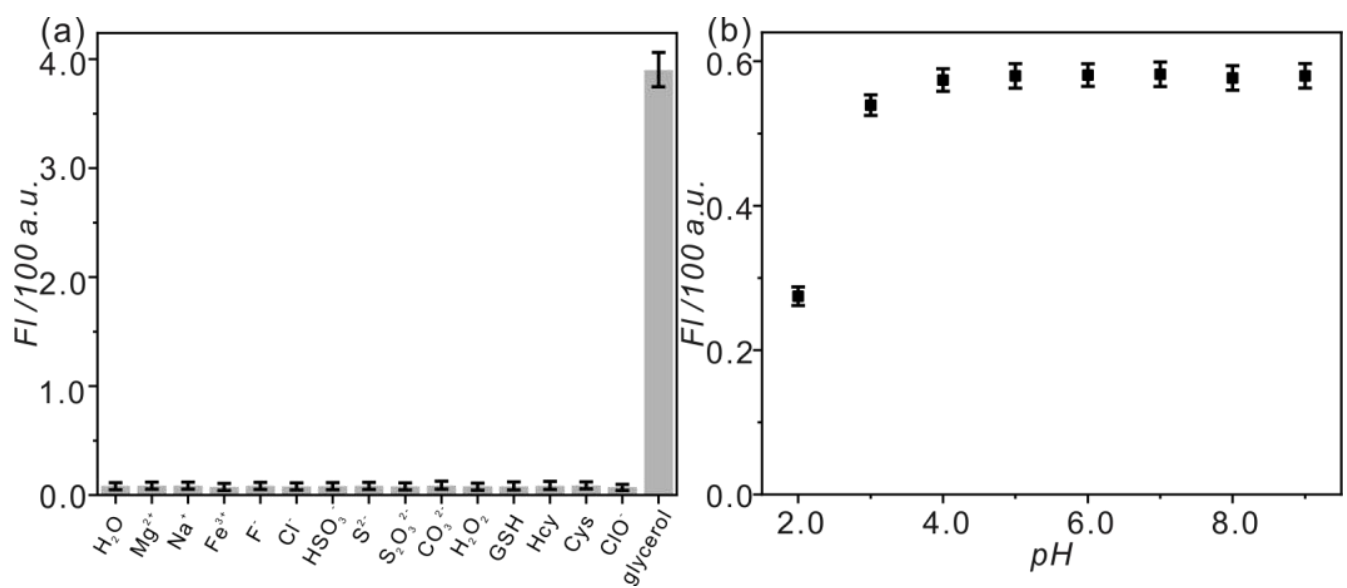

Figure S6. (a) Fluorescence responses of dye 1a $(10 \mu \mathrm{M})$ in the presence of $100 \mu \mathrm{M}$ of different biologically relevant analytes for $1 \mathrm{~h}$; (b) fluorescence intensity of dye $1 \mathrm{a}(10 \mu \mathrm{M})$ at different $\mathrm{pH}$ values in $\mathrm{B}-\mathrm{R}$ buffer containing $50 \%$ glycerol $\left(\lambda_{\mathrm{ex}}=605 \mathrm{~nm}\right.$, slit widths: $\left.3 \mathrm{~nm} / 5 \mathrm{~nm}\right)$, the data were shown as mean $\pm \operatorname{SD}(n=3)$.
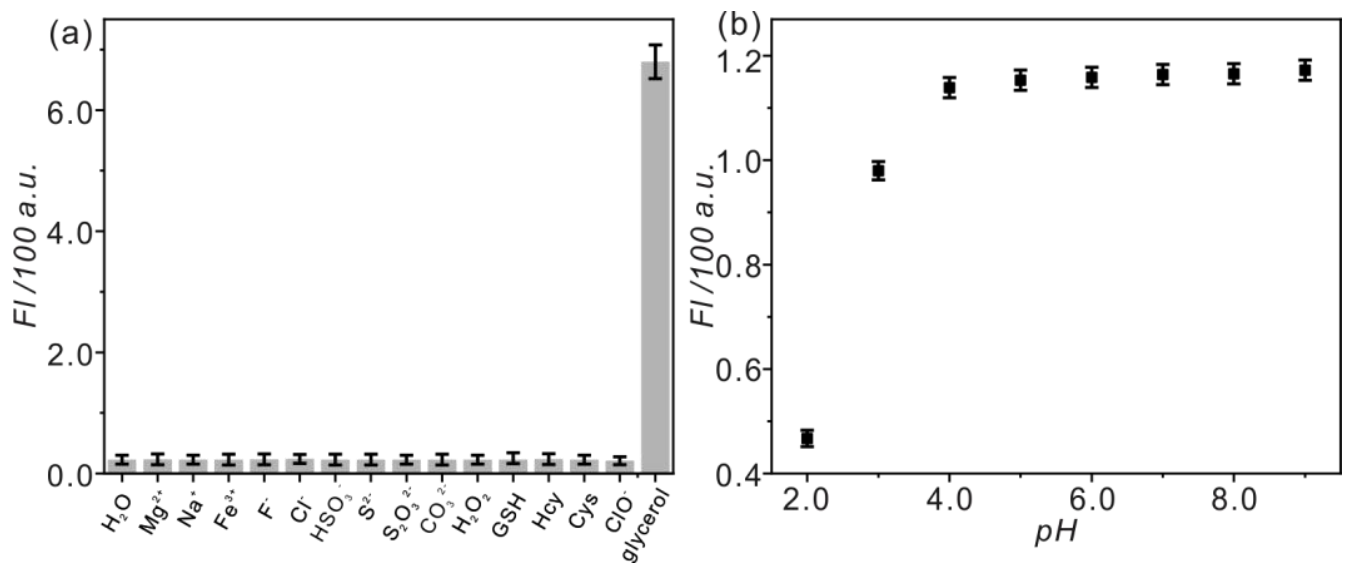

Figure S7. (a) Fluorescence responses of dye $\mathbf{1 b}(10 \mu \mathrm{M})$ in the presence of $100 \mu \mathrm{M}$ of different biologically relevant analytes for $1 \mathrm{~h}$; (b) fluorescence intensity of dye $\mathbf{1 b}(10 \mu \mathrm{M})$ at different $\mathrm{pH}$ values in $\mathrm{B}-\mathrm{R}$ buffer containing $50 \%$ glycerol $\left(\lambda_{\mathrm{ex}}=605 \mathrm{~nm}\right.$, slit widths: $\left.3 \mathrm{~nm} / 5 \mathrm{~nm}\right)$, the data were shown as mean \pm SD $(n=3)$.
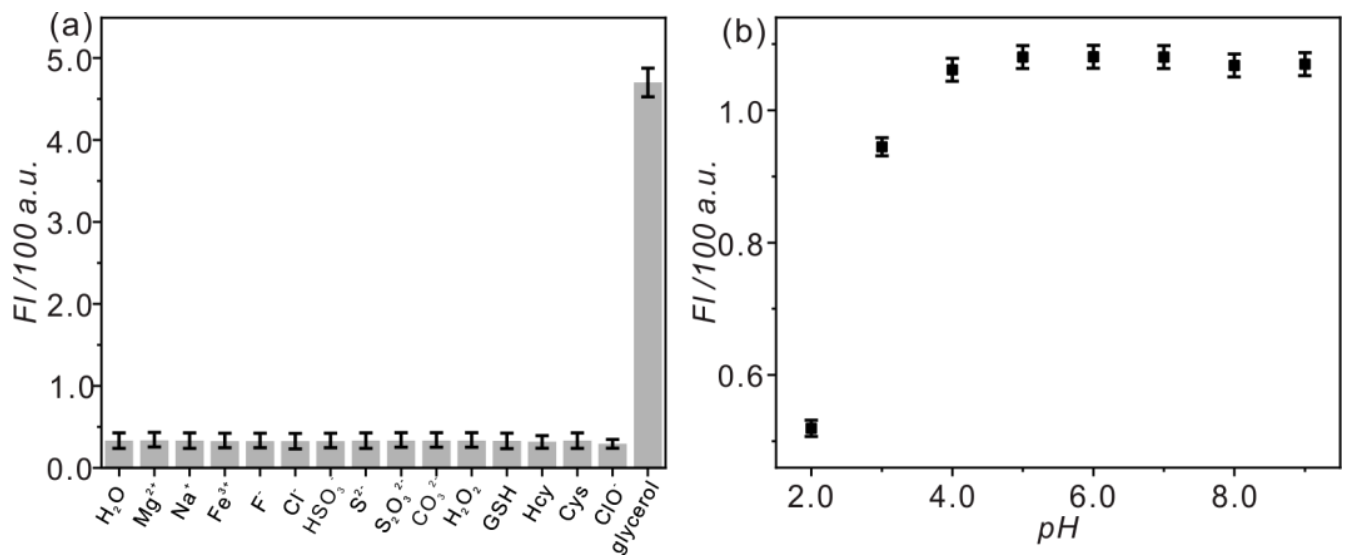

Figure S8. (a) Fluorescence responses of dye 1c $(10 \mu \mathrm{M})$ in the presence of $100 \mu \mathrm{M}$ of different biologically relevant analytes for $1 \mathrm{~h}$; (b) fluorescence intensity of dye 1c $(10 \mu \mathrm{M})$ at different $\mathrm{pH}$ values in $\mathrm{B}-\mathrm{R}$ buffer containing $50 \%$ glycerol $\left(\lambda_{\mathrm{ex}}=605 \mathrm{~nm}\right.$, slit widths: $\left.3 \mathrm{~nm} / 3 \mathrm{~nm}\right)$, the data were shown as mean $\pm \mathrm{SD}(\mathrm{n}=3)$. 

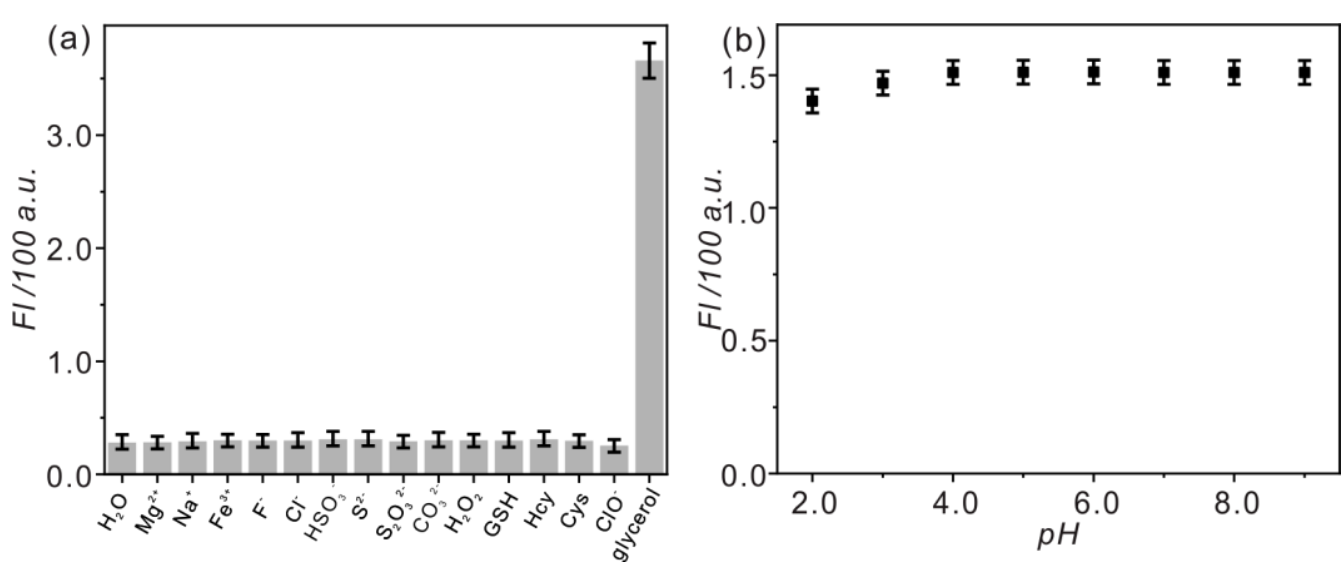

Figure S9. (a) Fluorescence responses of dye $1 \mathbf{d}(10 \mu \mathrm{M})$ in the presence of $100 \mu \mathrm{M}$ of different biologically relevant analytes for $1 \mathrm{~h}$; (b) fluorescence intensity of dye $\mathbf{1 d}(10 \mu \mathrm{M})$ at different pH values in $B-R$ buffer containing $50 \%$ glycerol $\left(\lambda_{\mathrm{ex}}=605 \mathrm{~nm}\right.$, slit widths: $\left.3 \mathrm{~nm} / 1.5 \mathrm{~nm}\right)$, the data were shown as mean \pm SD $(n=3)$.
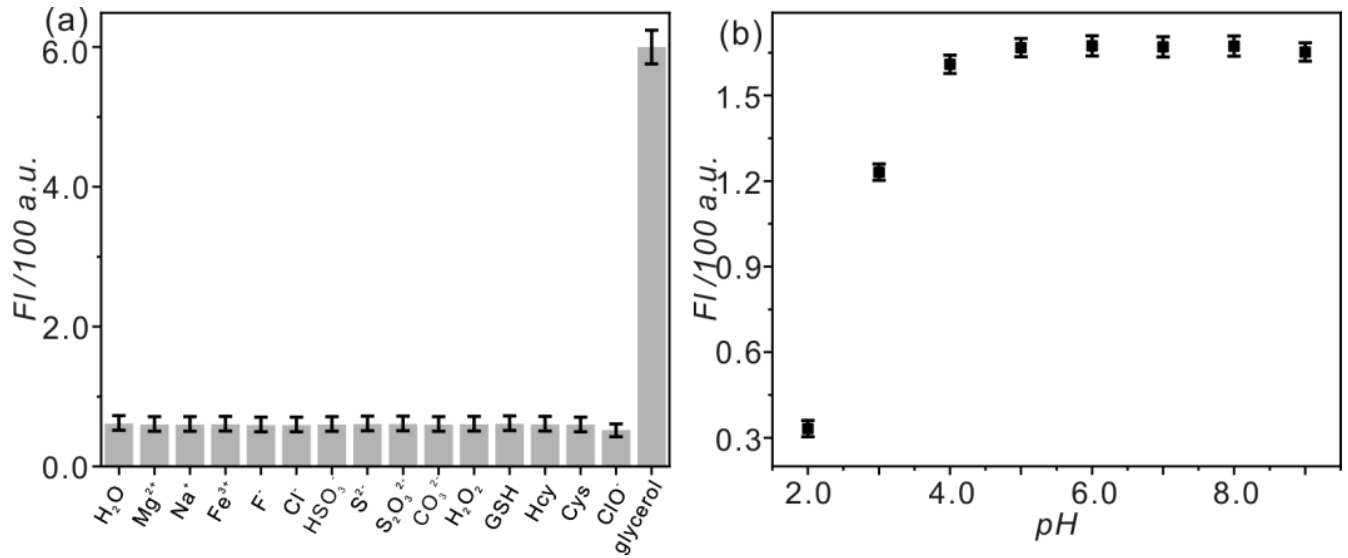

Figure S10. (a) Fluorescence responses of dye $1 \mathrm{e}(10 \mu \mathrm{M})$ in the presence of $100 \mu \mathrm{M}$ of different biologically relevant analytes for $1 \mathrm{~h}$; (b) fluorescence intensity of dye 1e $(10 \mu \mathrm{M})$ at different $\mathrm{pH}$ values in B-R buffer containing $50 \%$ glycerol $\left(\lambda_{\mathrm{ex}}=605 \mathrm{~nm}\right.$, slit widths: $\left.3 \mathrm{~nm} / 3 \mathrm{~nm}\right)$, the data were shown as mean $\pm S D(n=3)$.
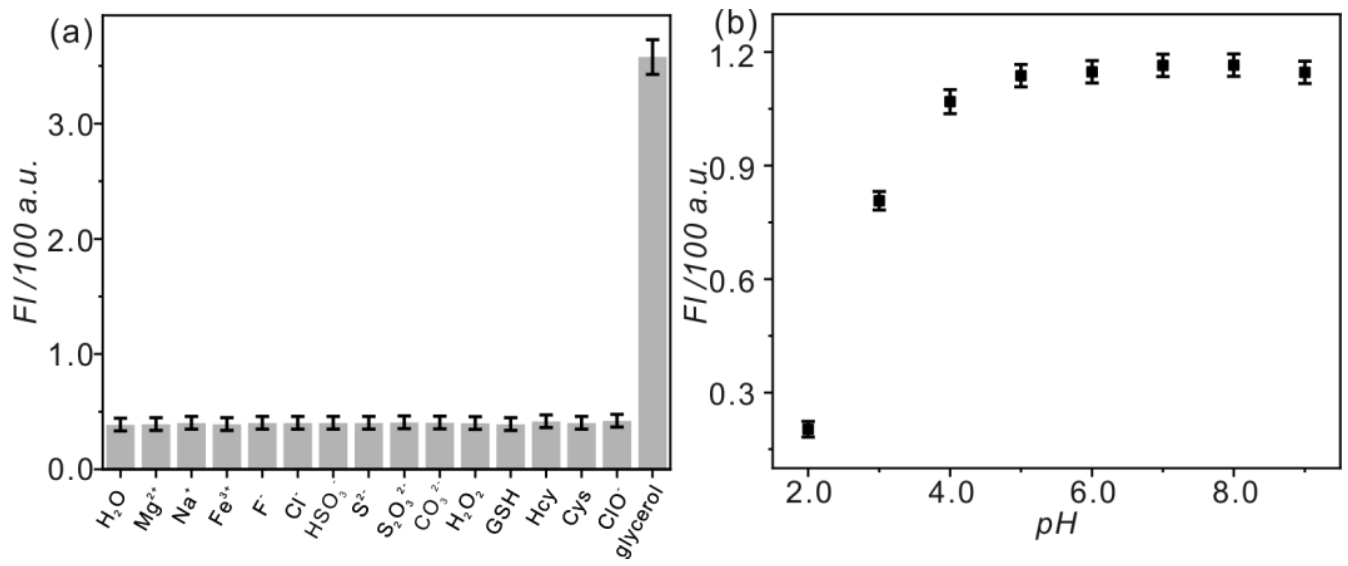

Figure S11. (a) Fluorescence responses of dye $1 \mathbf{1 f}(10 \mu \mathrm{M})$ in the presence of $100 \mu \mathrm{M}$ of different biologically relevant analytes for $1 \mathrm{~h}$; (b) fluorescence intensity of dye $1 \mathrm{f}(10 \mu \mathrm{M})$ at different $\mathrm{pH}$ values in B-R buffer containing $50 \%$ glycerol $\left(\lambda_{\mathrm{ex}}=605 \mathrm{~nm}\right.$, slit widths: $\left.3 \mathrm{~nm} / 3 \mathrm{~nm}\right)$, the data were shown as mean $\pm \mathrm{SD}(\mathrm{n}=3)$. 

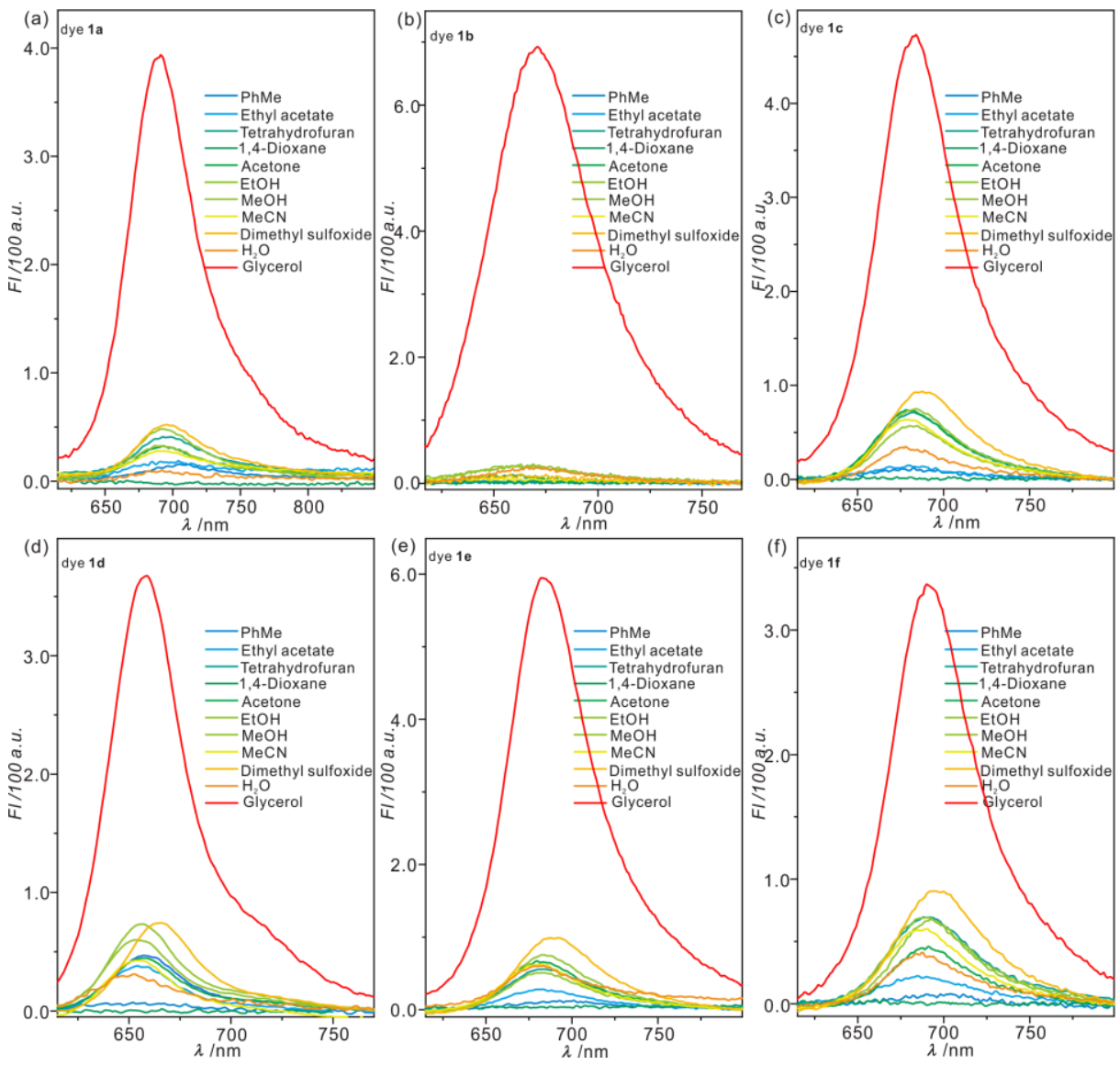

Figure S12. Fluorescence spectra of dyes 1a-f in various solvents with different polarities: (a) dye 1a, $\lambda_{\mathrm{ex}}=$ $605 \mathrm{~nm}$, slit widths: $3 \mathrm{~nm} / 5 \mathrm{~nm}$; (b) dye 1b, $\lambda_{\mathrm{ex}}=605 \mathrm{~nm}$, slit widths: $3 \mathrm{~nm} / 5 \mathrm{~nm}$; (c) dye 1c, $\lambda_{\mathrm{ex}}=605 \mathrm{~nm}$, slit widths: $3 \mathrm{~nm} / 3 \mathrm{~nm}$; (d) dye 1d, $\lambda_{\mathrm{ex}}=605 \mathrm{~nm}$, slit widths: $3 \mathrm{~nm} / 1.5 \mathrm{~nm}$; (e) dye 1e, $\lambda_{\mathrm{ex}}=605 \mathrm{~nm}$, slit widths: 3 $\mathrm{nm} / 3 \mathrm{~nm}$; (f) dye 1f, $\lambda_{\mathrm{ex}}=605 \mathrm{~nm}$, slit widths: $3 \mathrm{~nm} / 3 \mathrm{~nm}$. 

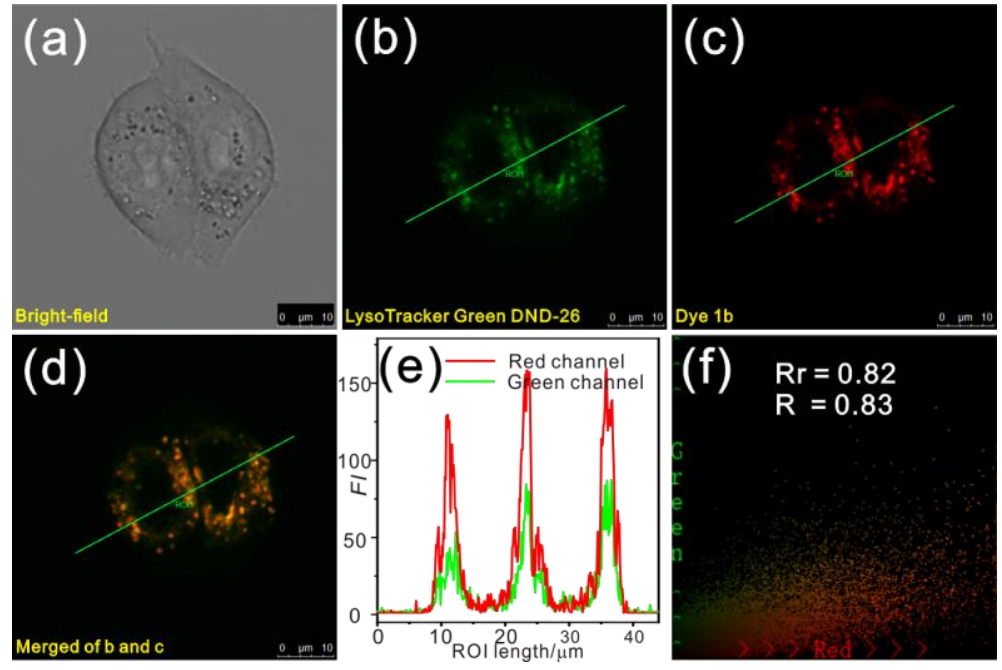

Figure S13. Fluorescence confocal images of HeLa cells with dye $\mathbf{1 b}$ and their ROls analysis. (a) Bright-field transmission images; (b) confocal images (green channel) of cells with LysoTracker Green DND-26 (100 nM); (c) confocal images (red channel) of cells with dye 1b; (d) merged images of (b) and (c); (e) fluorescence intensities of the regions of interest (ROls) in (b) and (c); (f) fluorescence intensity correlation plot.

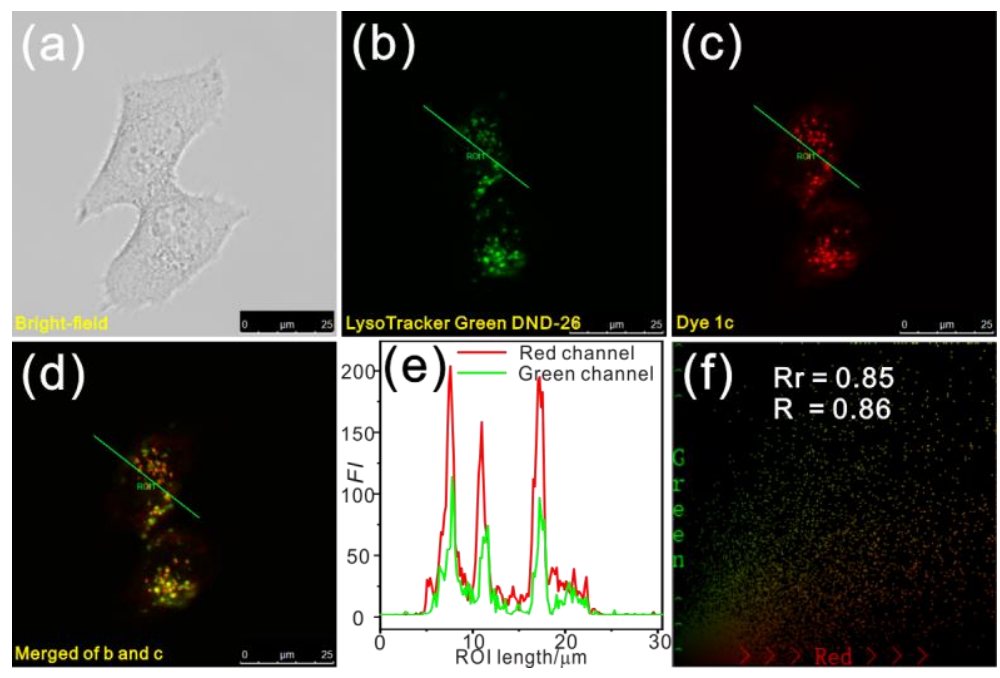

Figure S14. Fluorescence confocal images of HeLa cells with dye 1c and their ROls analysis. (a) Bright-field transmission images; (b) confocal images (green channel) of cells with LysoTracker Green DND-26 (100 nM); (c) confocal images (red channel) of cells with dye 1c; (d) merged images of (b) and (c); (e) fluorescence intensities of the regions of interest (ROIs) in (b) and (c); (f) fluorescence intensity correlation plot. 

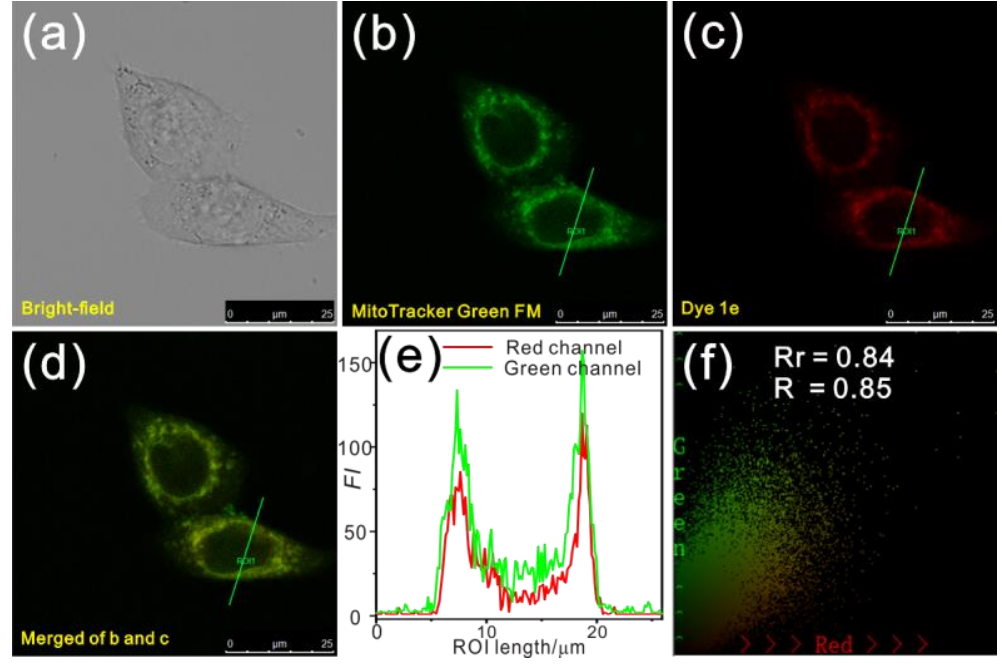

Figure S15. Fluorescence confocal images of HeLa cells with dye 1e and their ROls analysis. (a) Bright-field transmission images; (b) confocal images (green channel) of cells with MitoTracker Green FM (100 nM); (c) confocal images (red channel) of cells with dye 1e; (d) merged images of (b) and (c); (e) fluorescence intensities of the regions of interest (ROIs) in (b) and (c); (f) fluorescence intensity correlation plot.
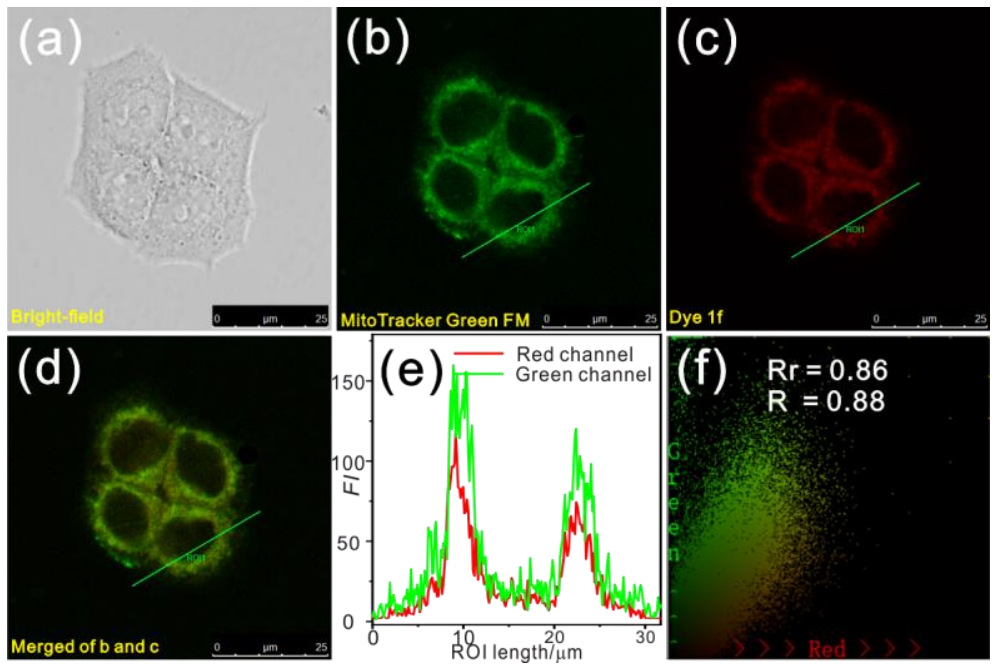

Figure S16. Fluorescence confocal images of HeLa cells with dye 1f and their ROls analysis. (a) Bright-field transmission images; (b) confocal images (green channel) of cells with MitoTracker Green FM (100 nM); (c) confocal images (red channel) of cells with dye 1f; (d) merged images of (b) and (c); (e) fluorescence intensities of the regions of interest (ROls) in (b) and (c); (f) fluorescence intensity correlation plot. 


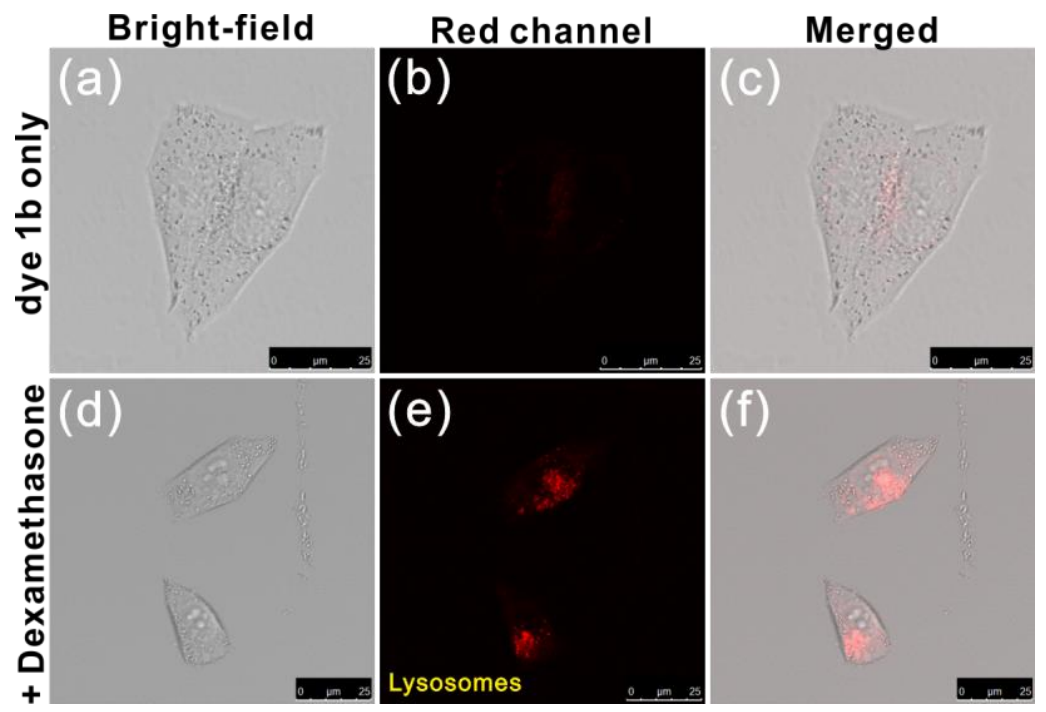

Figure S17. Confocal laser fluorescence images of HeLa cells: (a-c) HeLa cells incubated with dye $1 \mathrm{~b}(1 \mu \mathrm{M})$ for $20 \mathrm{~min}$; $(\mathrm{d}-\mathrm{f})$ HeLa cells treated with dexamethasone $(10 \mu \mathrm{M})$ for 30 min and dye $\mathbf{1 b}(1 \mu \mathrm{M})$ for another 20 $\min$.

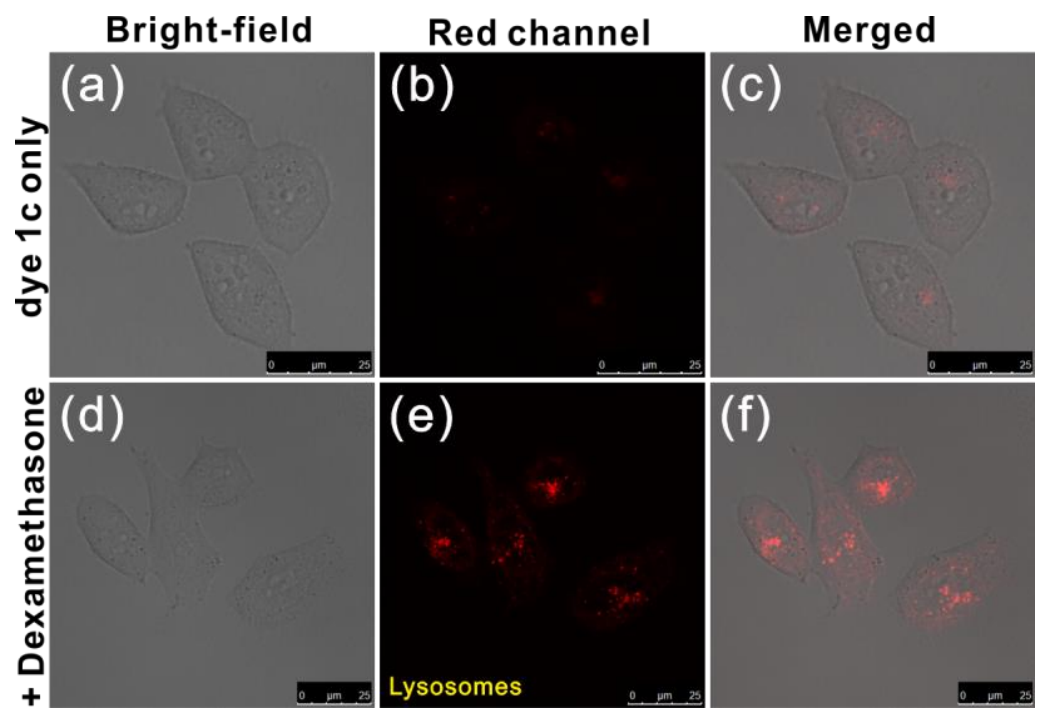

Figure S18. Confocal laser fluorescence images of HeLa cells: (a-c) HeLa cells incubated with dye 1c $(1 \mu \mathrm{M})$ for $20 \mathrm{~min}$; $(\mathrm{d}-\mathrm{f}) \mathrm{HeLa}$ cells treated with dexamethasone $(10 \mu \mathrm{M})$ for $30 \mathrm{~min}$ and dye $1 \mathrm{c}(1 \mu \mathrm{M})$ for another 20 $\min$. 


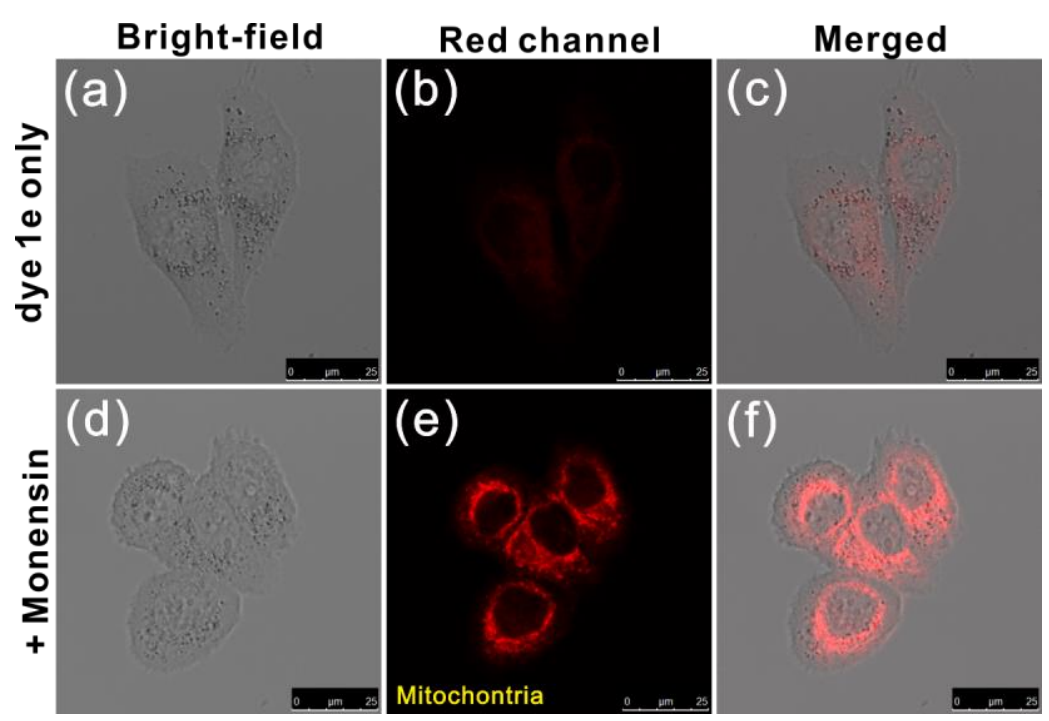

Figure S19. Confocal laser fluorescence images of HeLa cells: (a-c) HeLa cells incubated with dye 1e $(1 \mu \mathrm{M})$ for $20 \mathrm{~min}$; (d-f) HeLa cells treated with monensin $(10 \mu \mathrm{M})$ for $30 \mathrm{~min}$ and dye 1e $(1 \mu \mathrm{M})$ for another $20 \mathrm{~min}$.

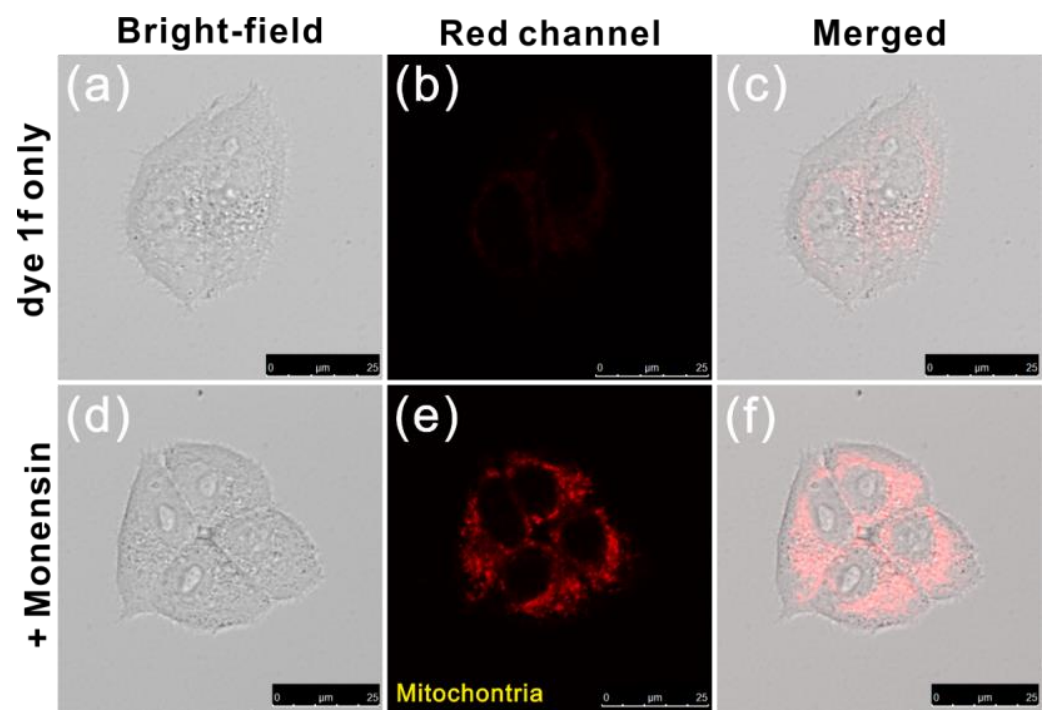

Figure S20. Confocal laser fluorescence images of HeLa cells: $(a-c)$ HeLa cells incubated with dye 1f $(1 \mu \mathrm{M})$ for $20 \mathrm{~min}$; (d-f) HeLa cells treated with monensin $(10 \mu \mathrm{M})$ for $30 \mathrm{~min}$ and dye $1 \mathrm{f}(1 \mu \mathrm{M})$ for another $20 \mathrm{~min}$. 


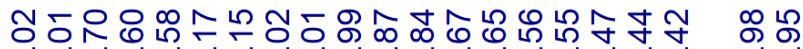
"
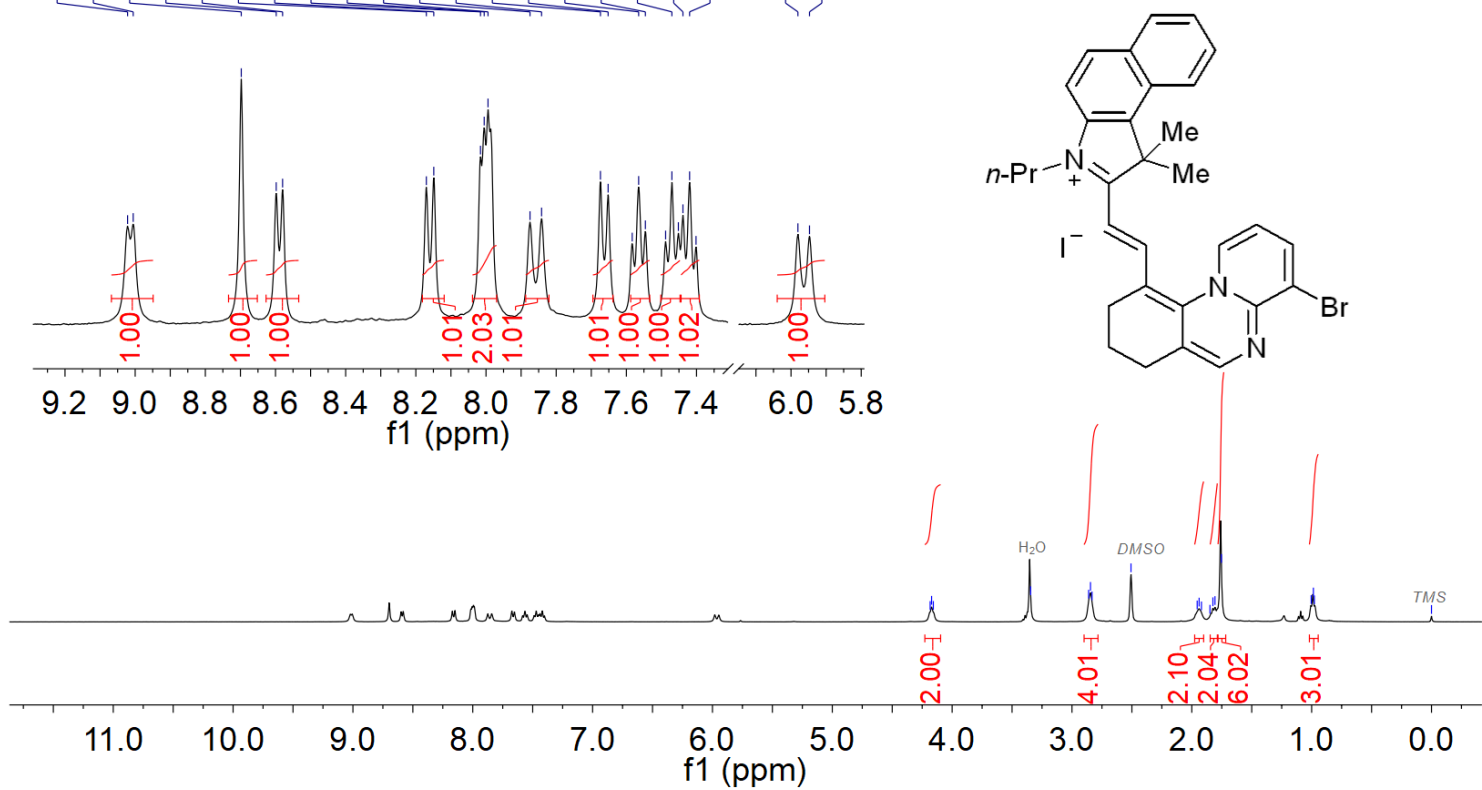

Figure S21. ${ }^{1} \mathrm{H}$ NMR of dye $\mathbf{1 a}$.

${ }^{1} \mathrm{H}$ NMR (400 MHZ,DMSO-d6)

每

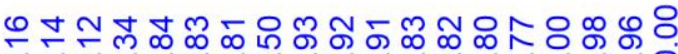

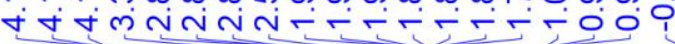
"ं

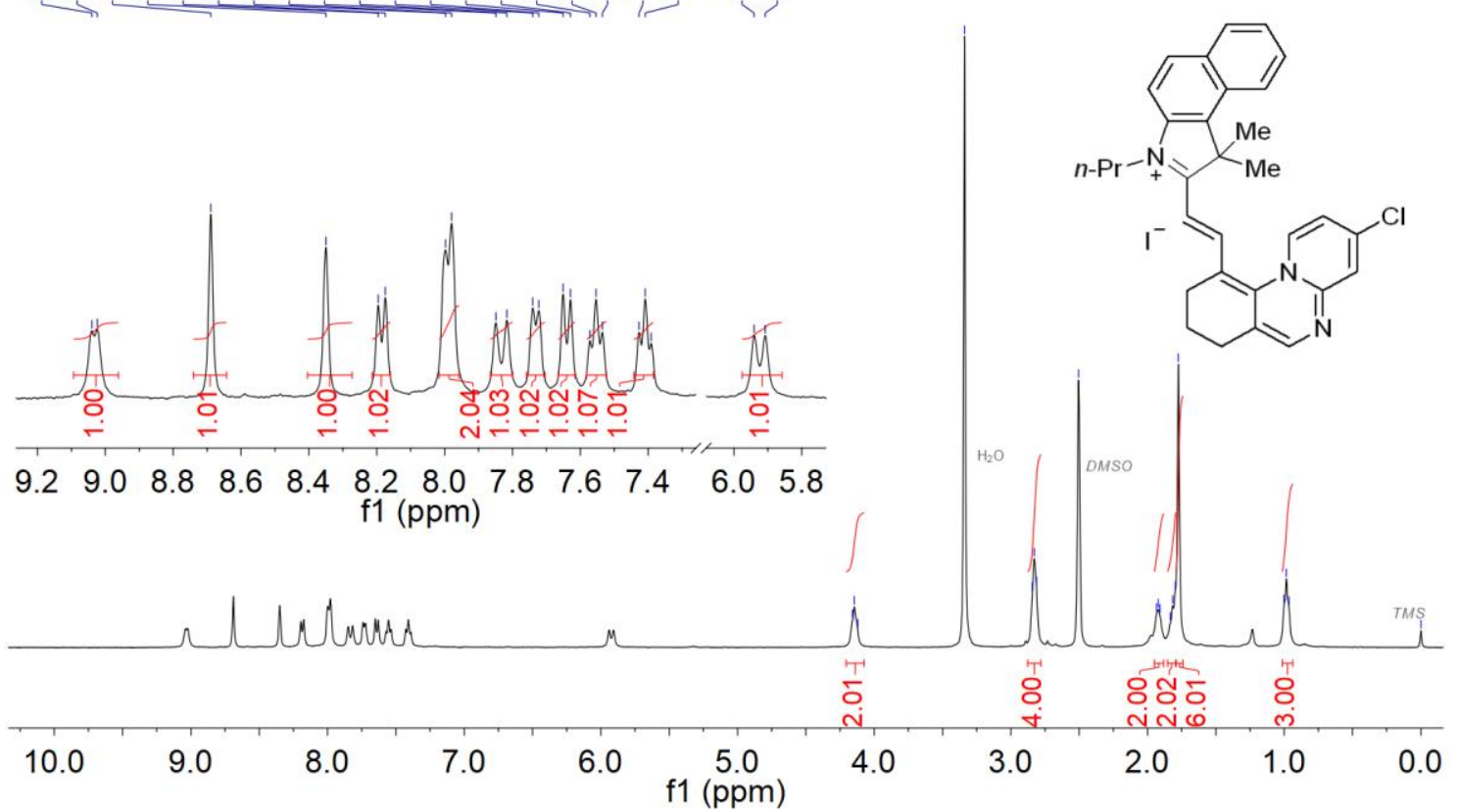

Figure S22. ${ }^{1} \mathrm{H}$ NMR of dye $\mathbf{1 b}$. 
'H NMR (400 MHz,DMSO-ds)

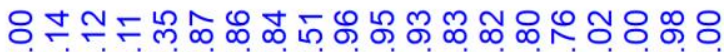

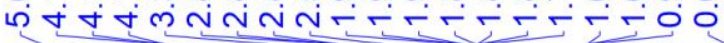

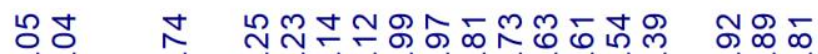

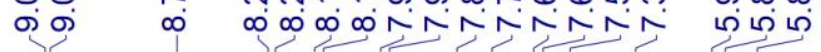
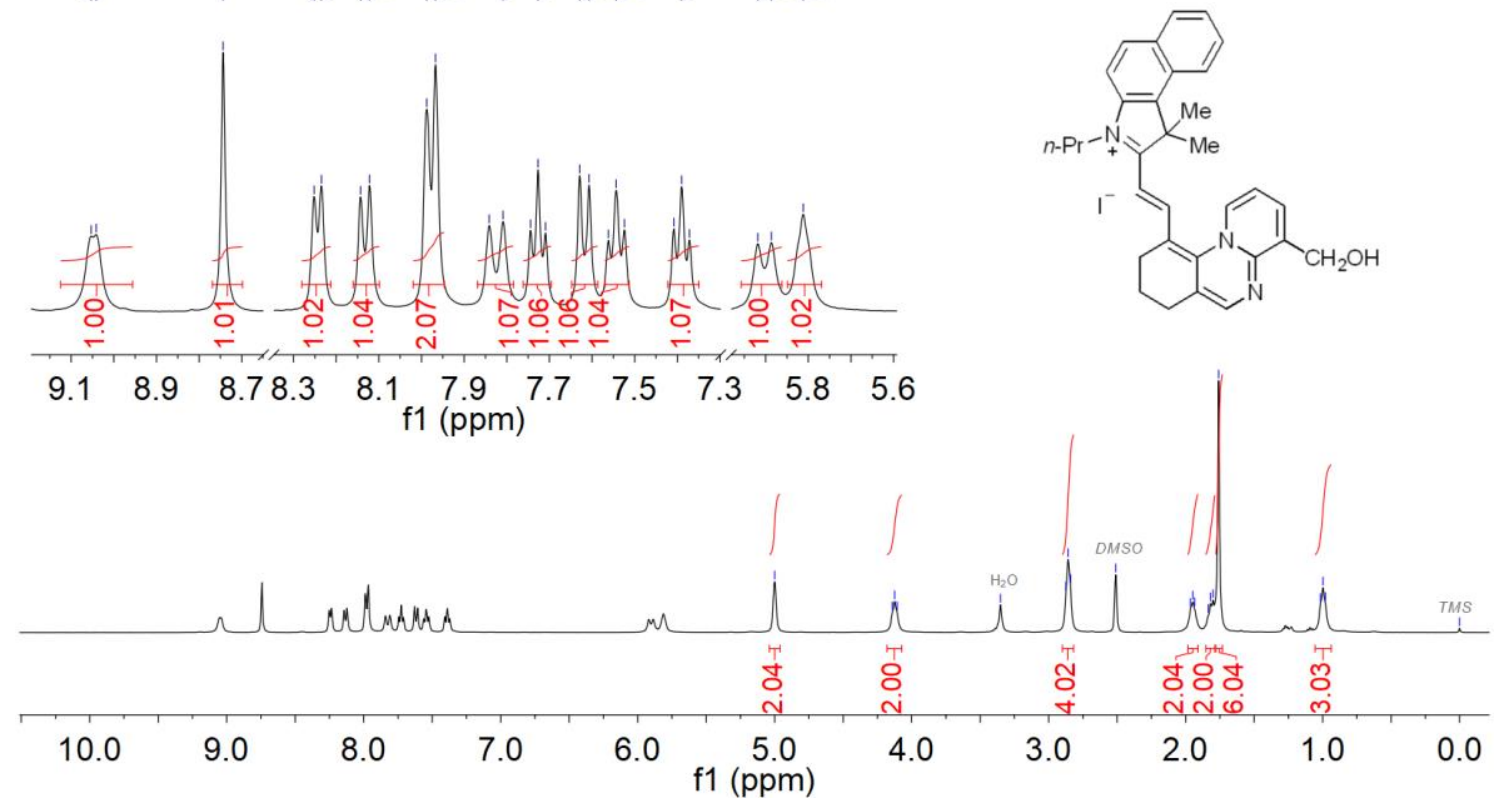

Figure S23. ${ }^{1} \mathrm{H}$ NMR of dye $\mathbf{1 c}$.

${ }^{1} \mathrm{H}$ NMR (400 MHz,DMSO-d

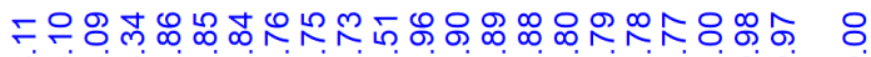

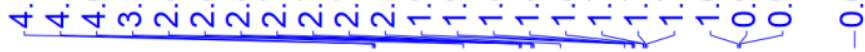

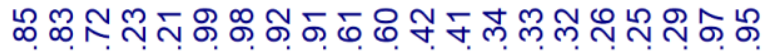

$\infty \infty \infty \infty \infty N N N$ NNNNNNNN
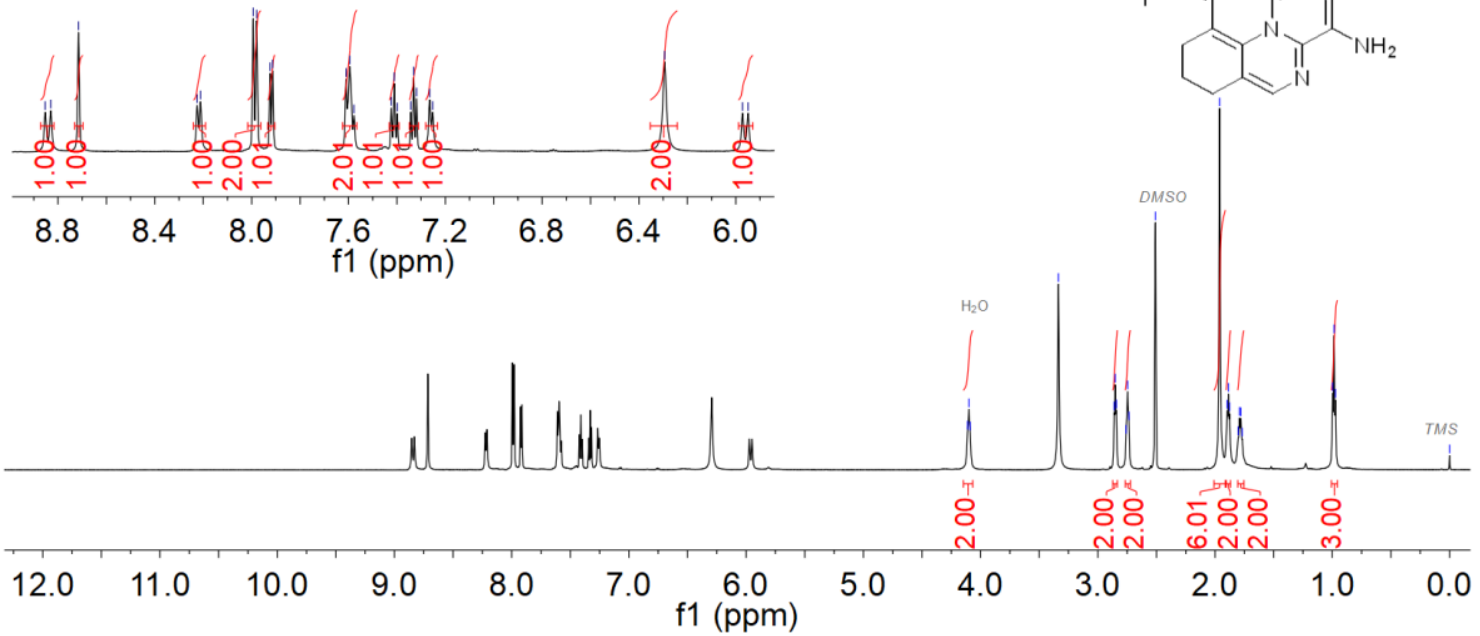

Figure S24. ${ }^{1} \mathrm{H}$ NMR of dye $\mathbf{1 d}$. 
'H NMR (400 MHz, DMSO-d

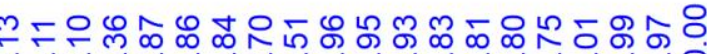

A

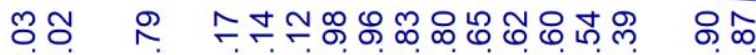

कं $\infty \infty_{\infty} \infty N N N N N N$
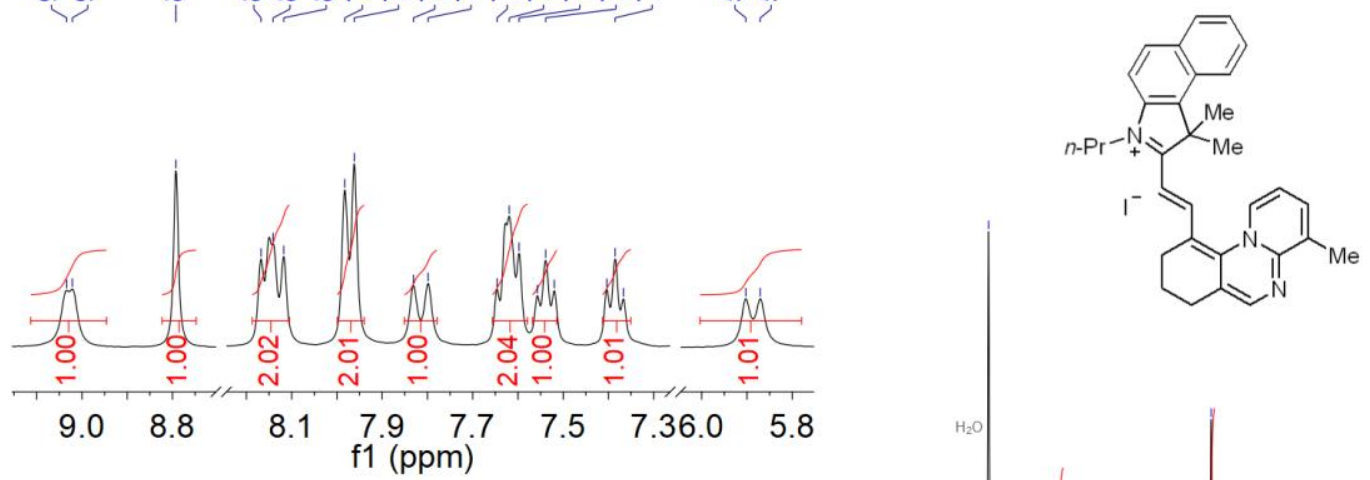

$\begin{array}{lllllllll}9.0 & 8.8 & 8.1 & 7.9 & 7.7 & 7.5 & 7.36 .0 & 5.8\end{array}$

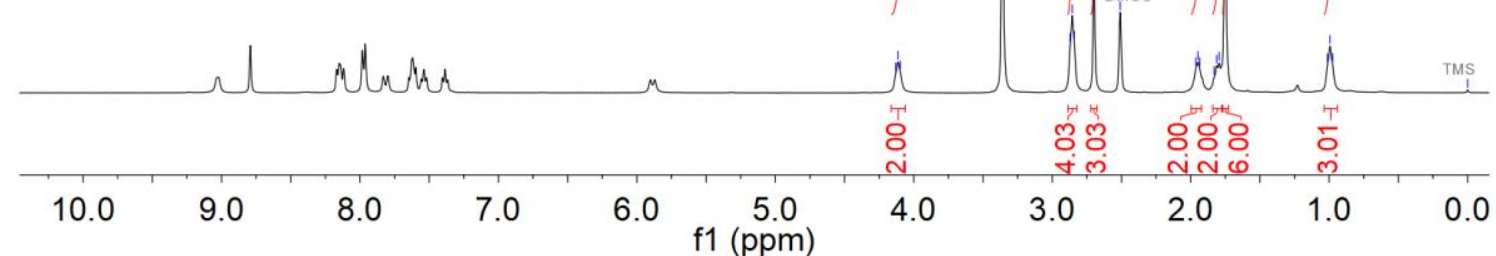

Figure S25. ${ }^{1} \mathrm{H}$ NMR of dye 1 e.

'H NMR $\left(400 \mathrm{MHz}, \mathrm{CDCl}_{2}\right)$

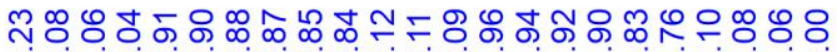

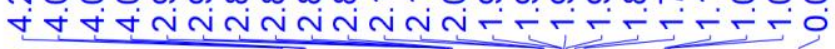

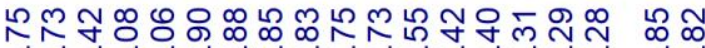

舟
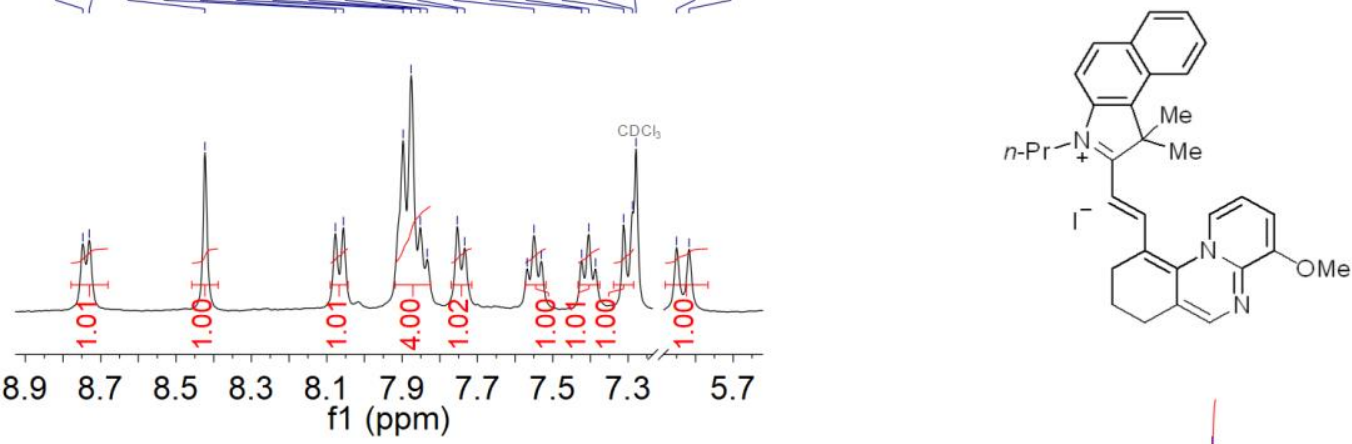

$\begin{array}{llllllllll}8.9 & 8.7 & 8.5 & 8.3 & 8.1 & 7.9 & 7.7 & 7.5 & 7.3 & 5.7\end{array}$

f1 (ppm)

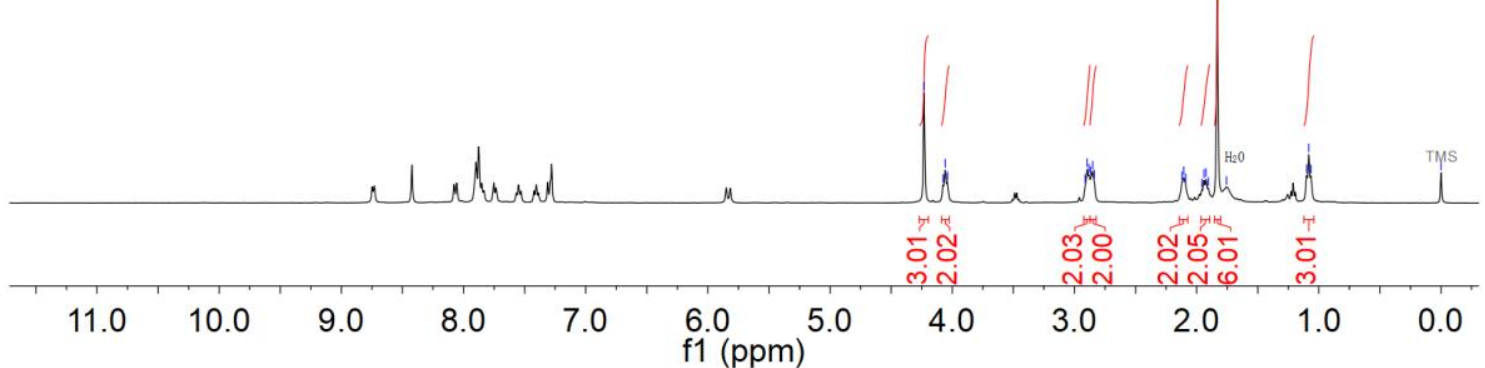

Figure S26. ${ }^{1} \mathrm{H}$ NMR of dye $1 \mathrm{f}$. 


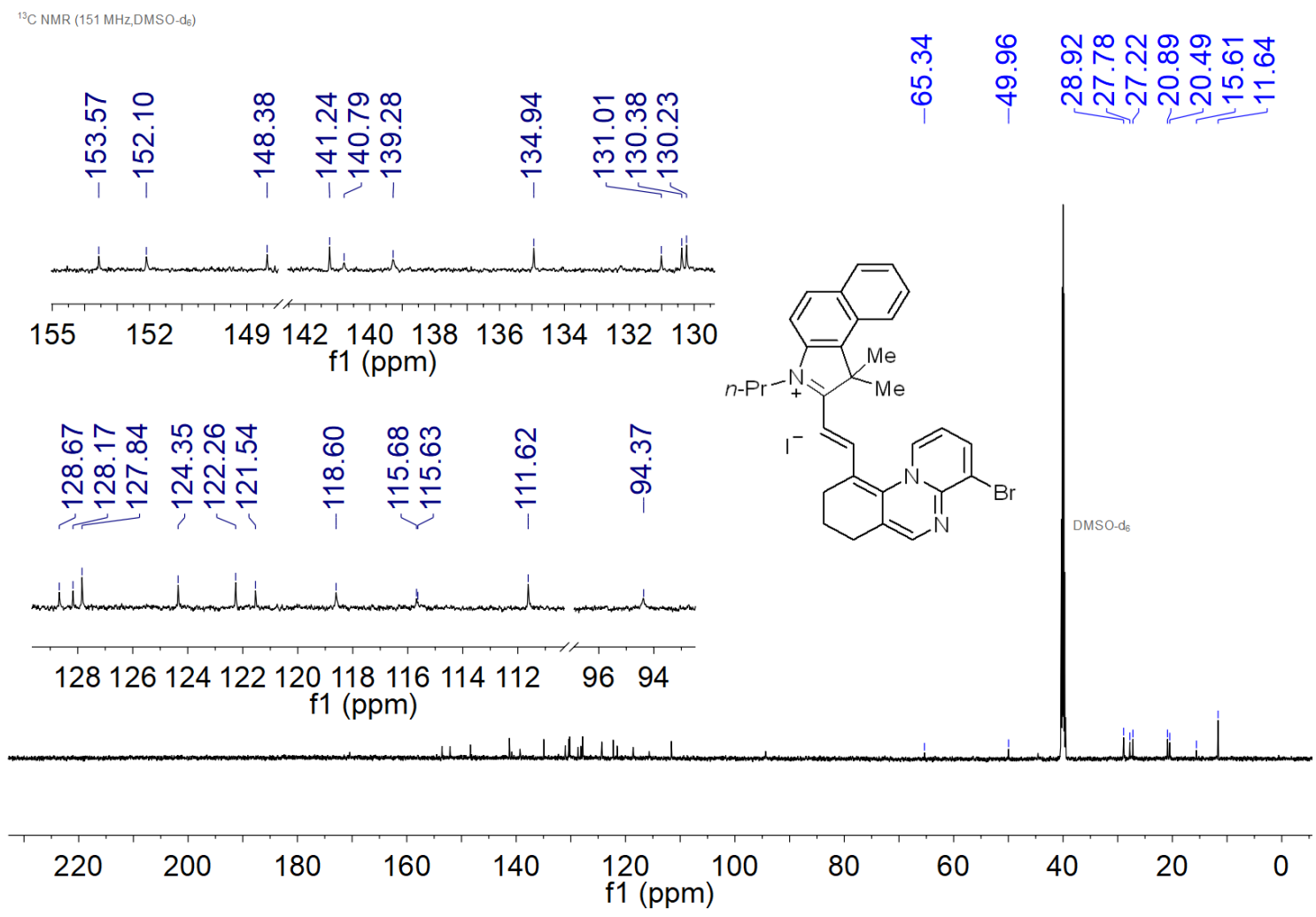

Figure S27. ${ }^{13} \mathrm{C}$ NMR of dye $\mathbf{1 a}$.

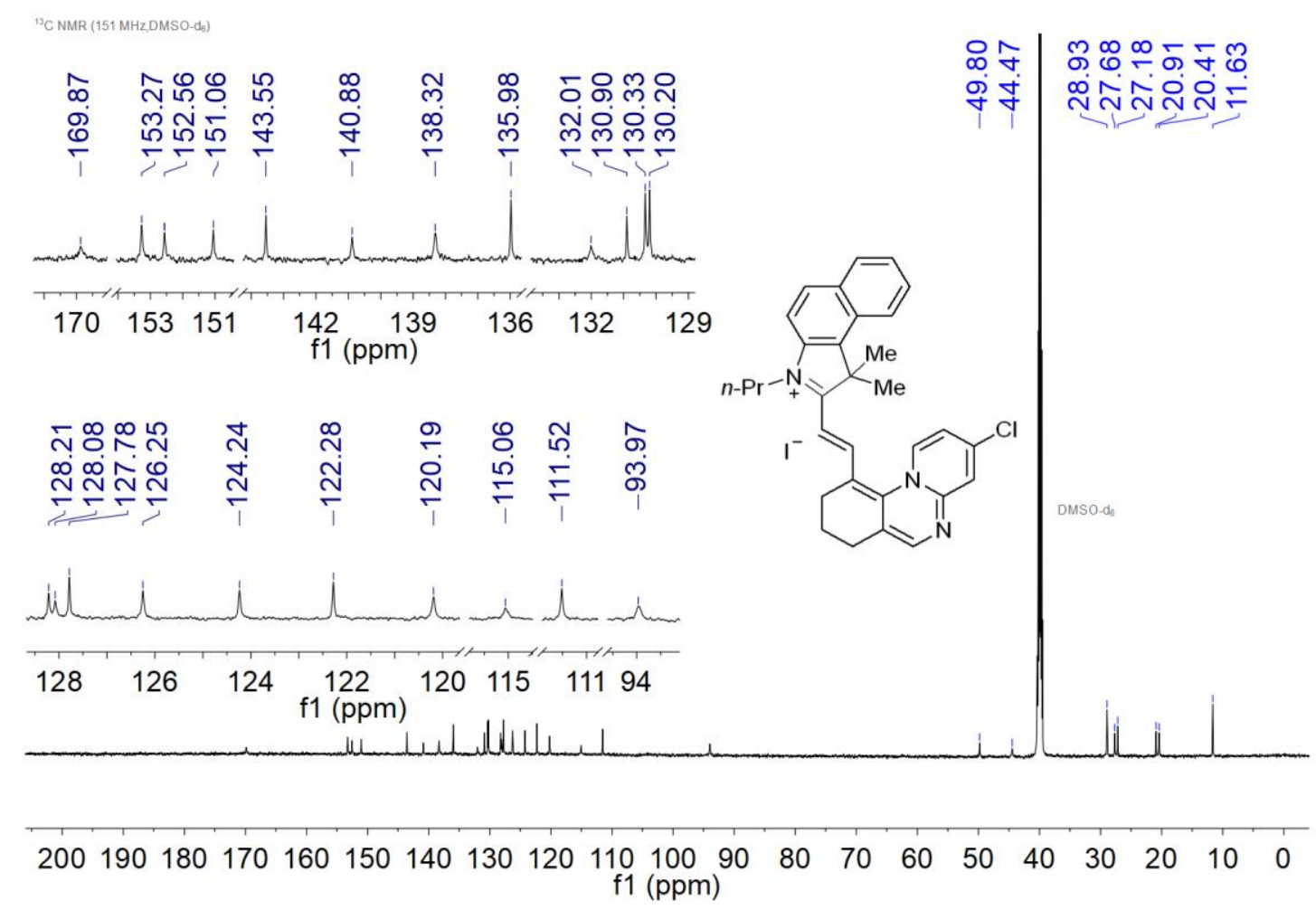

Figure S28. ${ }^{13} \mathrm{C}$ NMR of dye $\mathbf{1 b}$. 


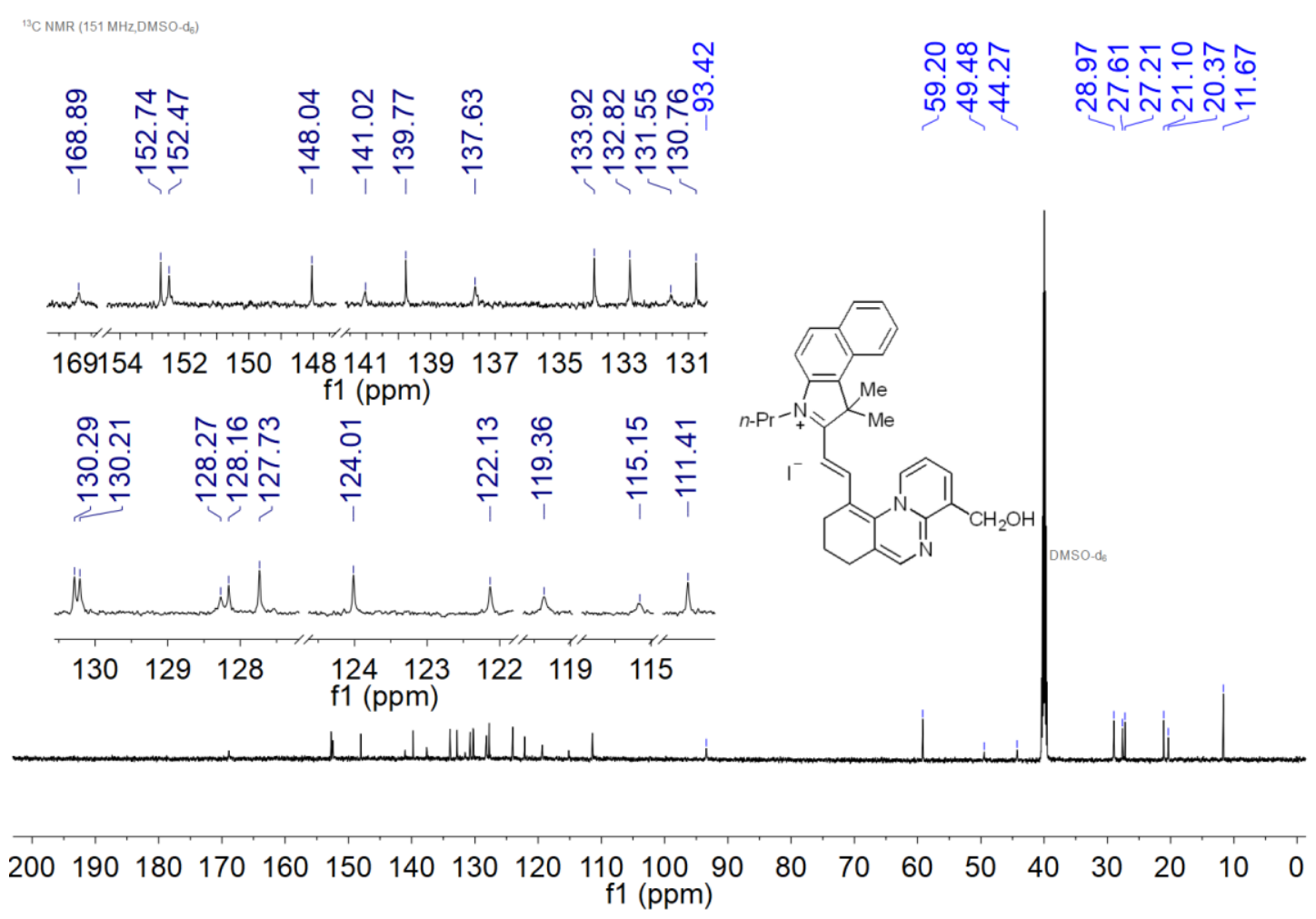

Figure S29. ${ }^{13} \mathrm{C}$ NMR of dye $\mathbf{1 c}$.

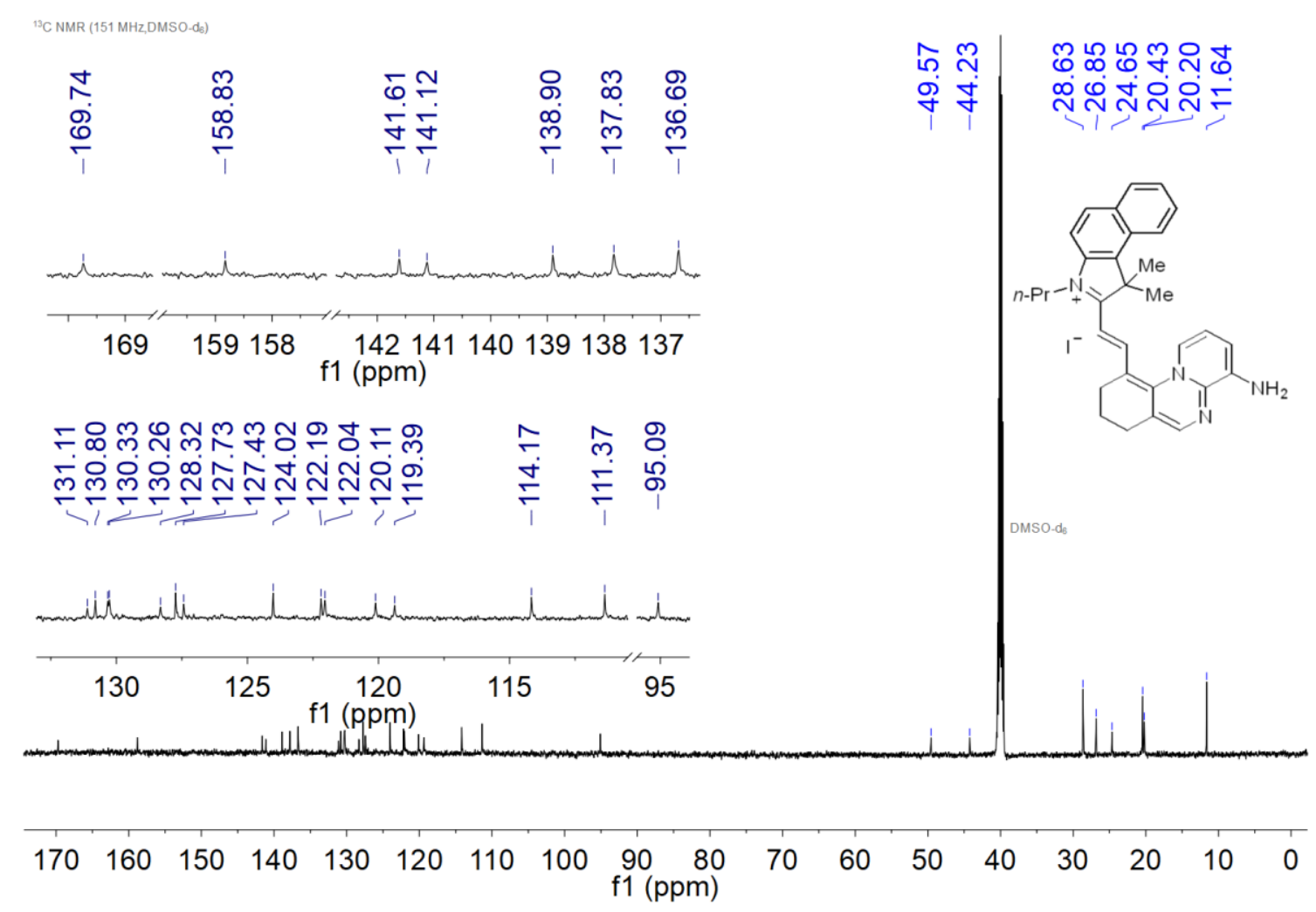

Figure S30. ${ }^{13} \mathrm{C}$ NMR of dye $\mathbf{1 d}$. 


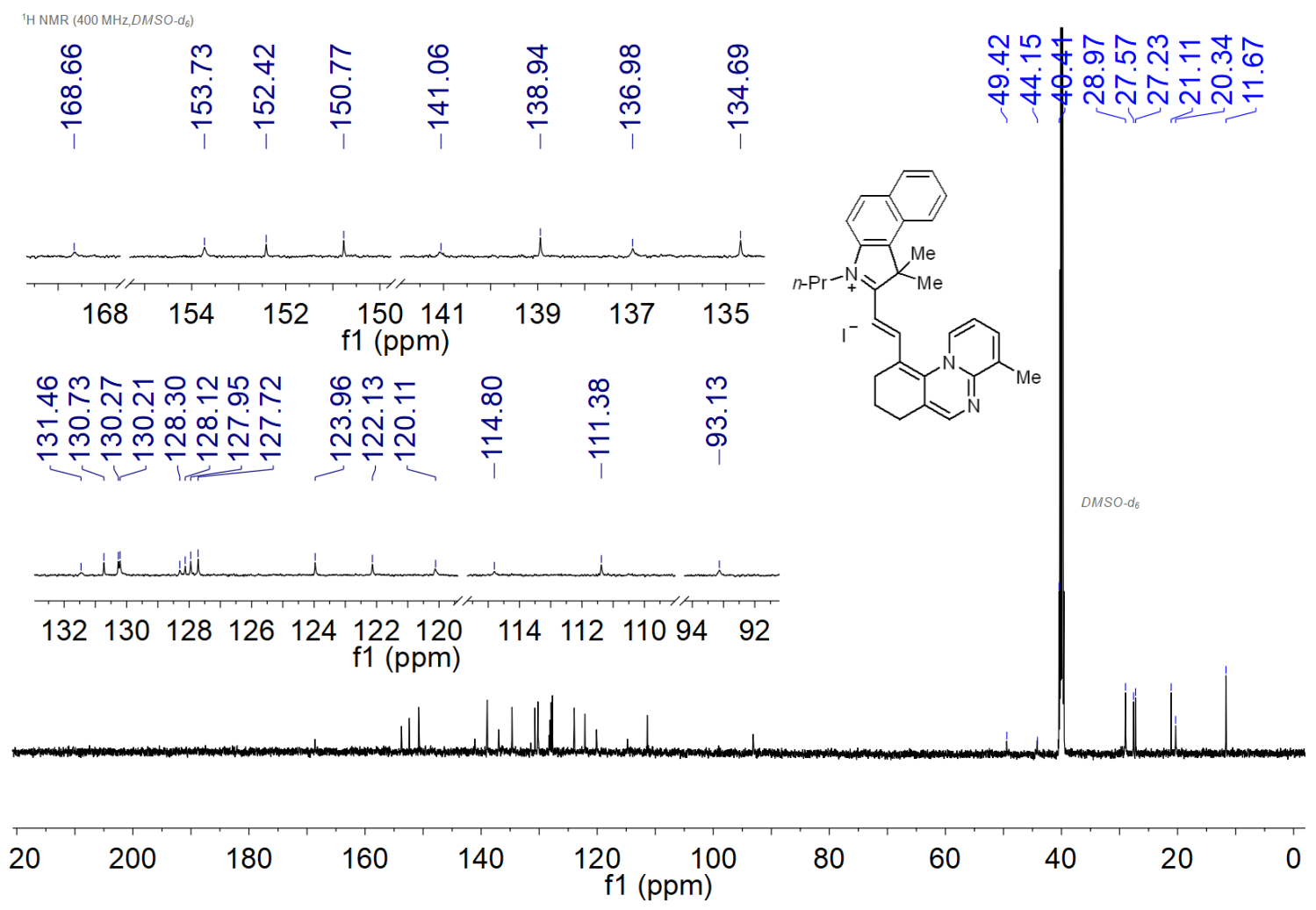

Figure S31. ${ }^{13} \mathrm{C}$ NMR of dye $1 \mathrm{e}$.

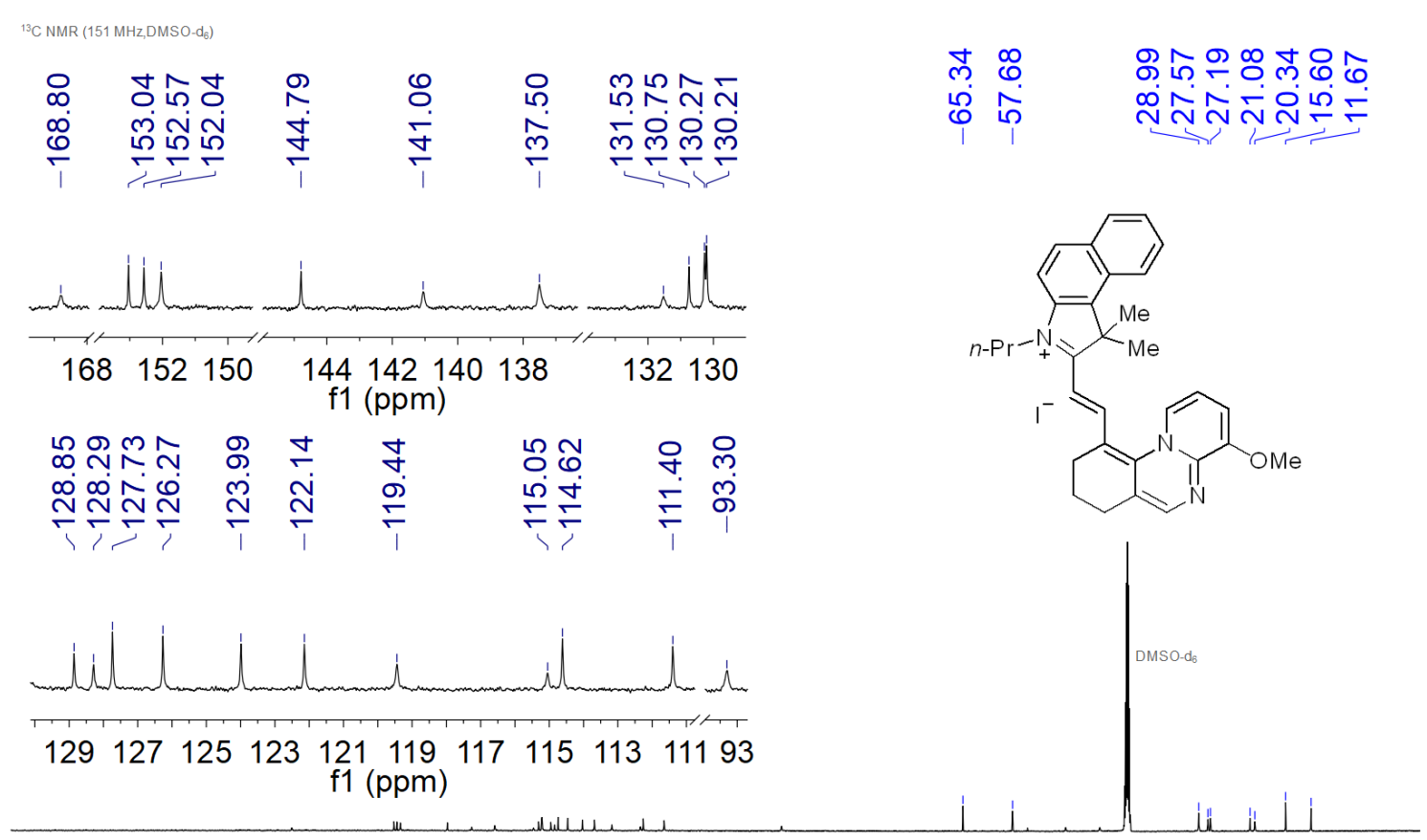

$\left.210200190180170160150140130120 \begin{array}{c}110(100 \\ \mathrm{f} 1(\mathrm{ppm})\end{array}\right)$

Figure S32. ${ }^{13} \mathrm{C}$ NMR of dye $1 \mathbf{f}$. 
Acquisition Parameter

Source Type

Focus

Scan End

ESI

Not active

$50 \mathrm{~m} / \mathrm{z}$

$3000 \mathrm{~m} / \mathrm{z}$
Ion Polarity

Set Capillary

Set End Plate Offset

Set Collision Cell RF
Positive

$4500 \mathrm{~V}$

$-500$

$200.0 \mathrm{Vpp}$

$\begin{array}{ll}\text { Set Nebulizer } & 1.0 \mathrm{Bar} \\ \text { Set Dry Heater } & 180 \text { 瘷 } \\ \text { Set Dry Gas } & 4.0 \mathrm{I} / \mathrm{min} \\ \text { Set Divert Valve } & \text { Waste }\end{array}$

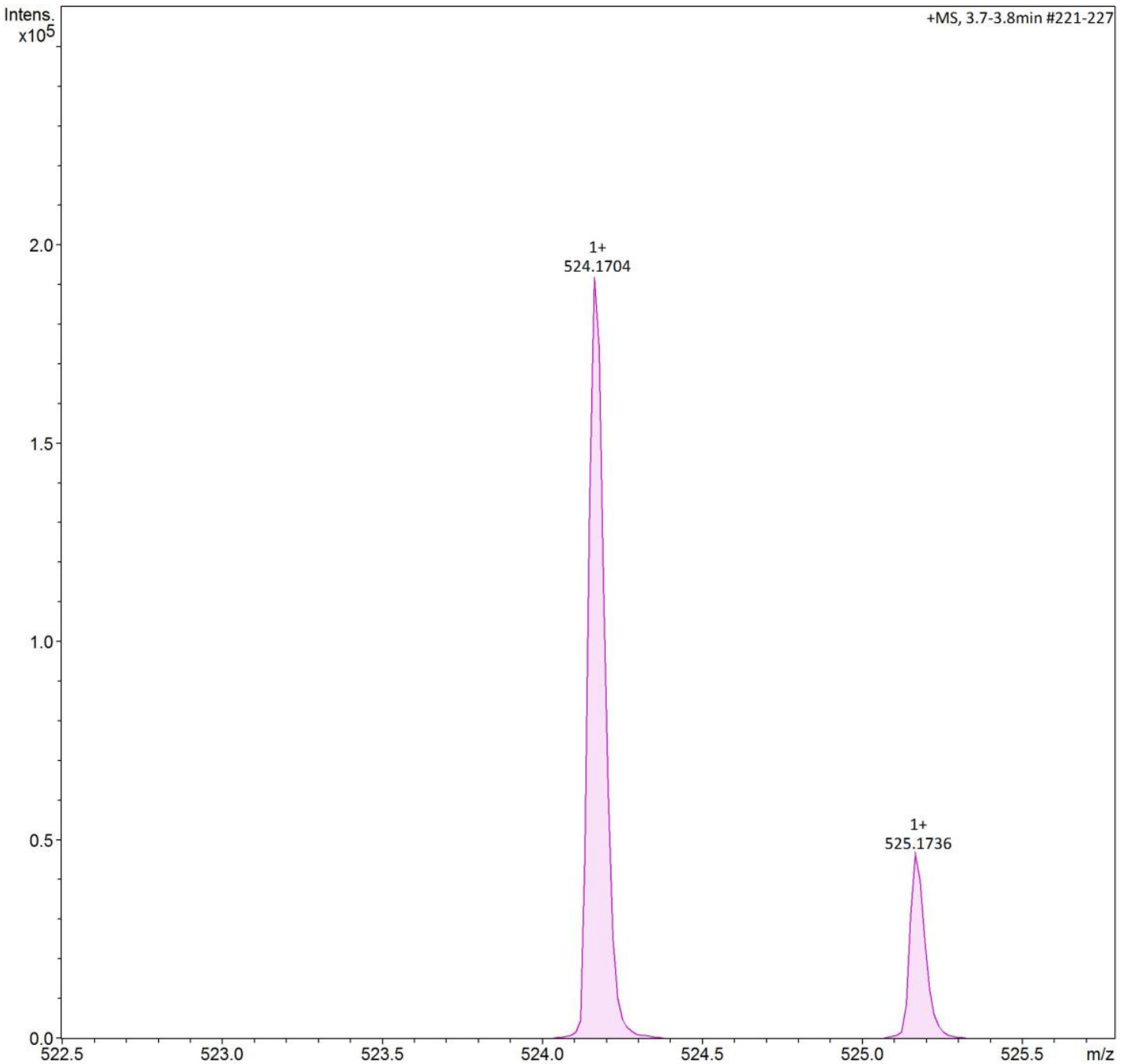

Figure S33. HR-MS $\left(\mathrm{ESI}^{+}\right)$of dye $\mathbf{1 a}$. 
Acquisition Parameter

Source Type

Focus

Scan Begin

ESI

Not active

$50 \mathrm{~m} / \mathrm{z}$

$3000 \mathrm{~m} / \mathrm{z}$

$\begin{array}{ll}\text { Set Nebulizer } & 1.0 \mathrm{Bar} \\ \text { Set Dry Heater } & 180 \text { 癈 } \\ \text { Set Dry Gas } & 4.0 \mathrm{I} / \mathrm{min} \\ \text { Set Divert Valve } & \text { Waste }\end{array}$

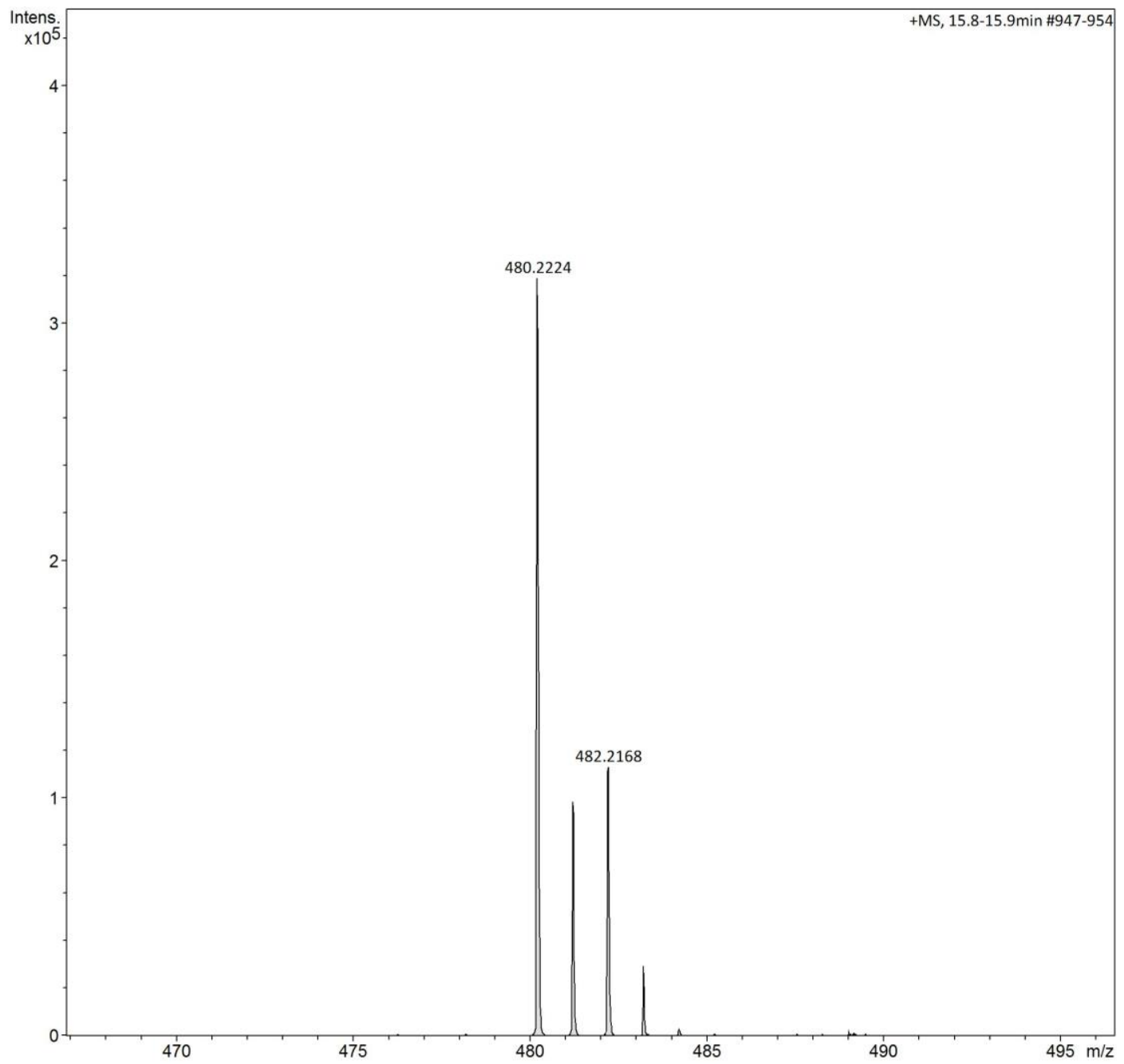

Figure S34. HR-MS (ESI') of dye $\mathbf{1 b}$. 
Acquisition Parameter

Source Type

Focus

ESI

Scan Begin

Not active

Scan End

Ion Polarity

Set Capillary

Set End Plate Offset

Positive

$4500 \mathrm{~V}$

Set Collision Cell RF $\quad 200.0$ Vpp

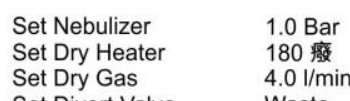

Set Divert Valve

Waste

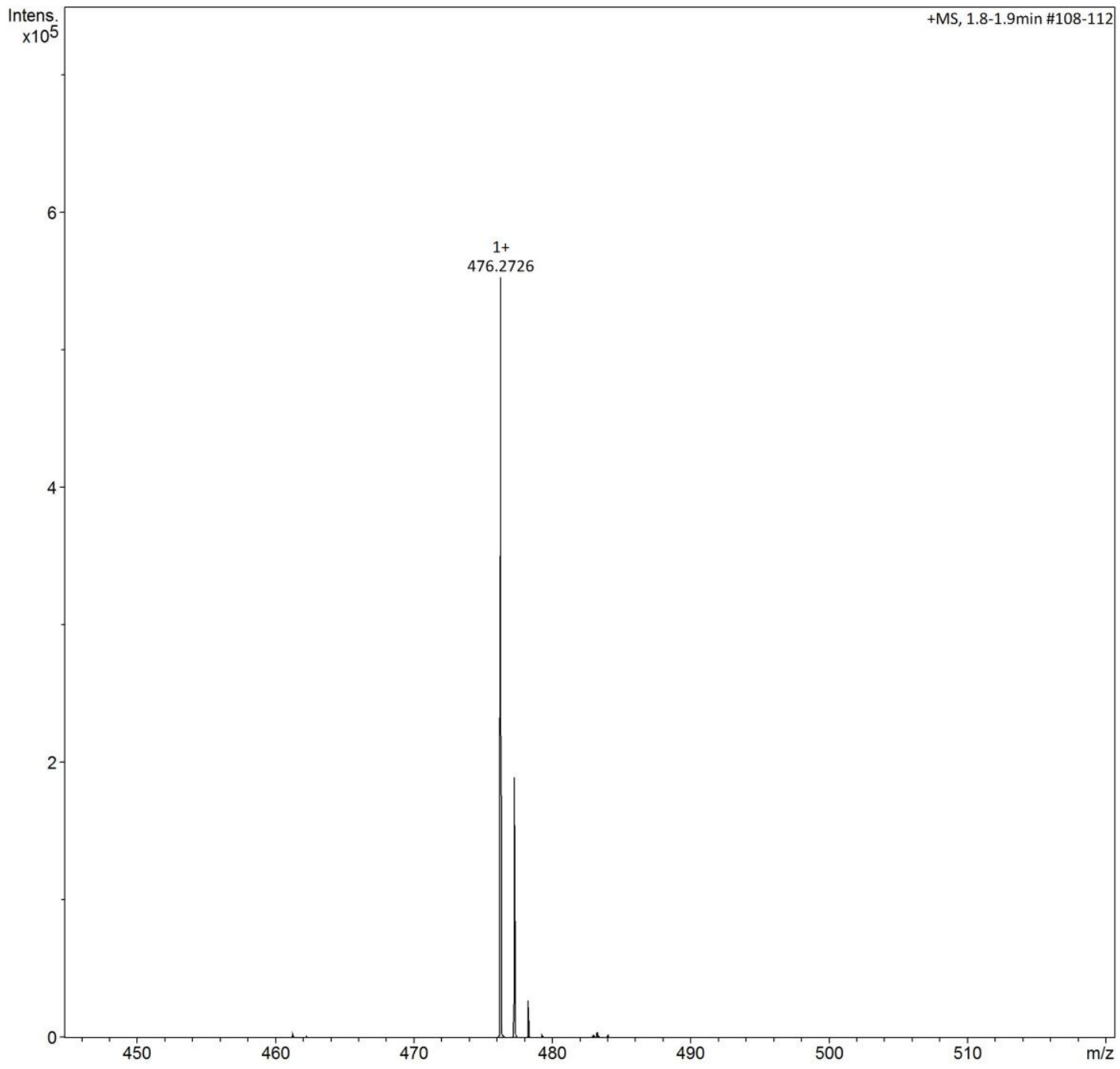

Figure S35. HR-MS $\left(\mathrm{ESI}^{+}\right)$of dye $\mathbf{1 c}$. 


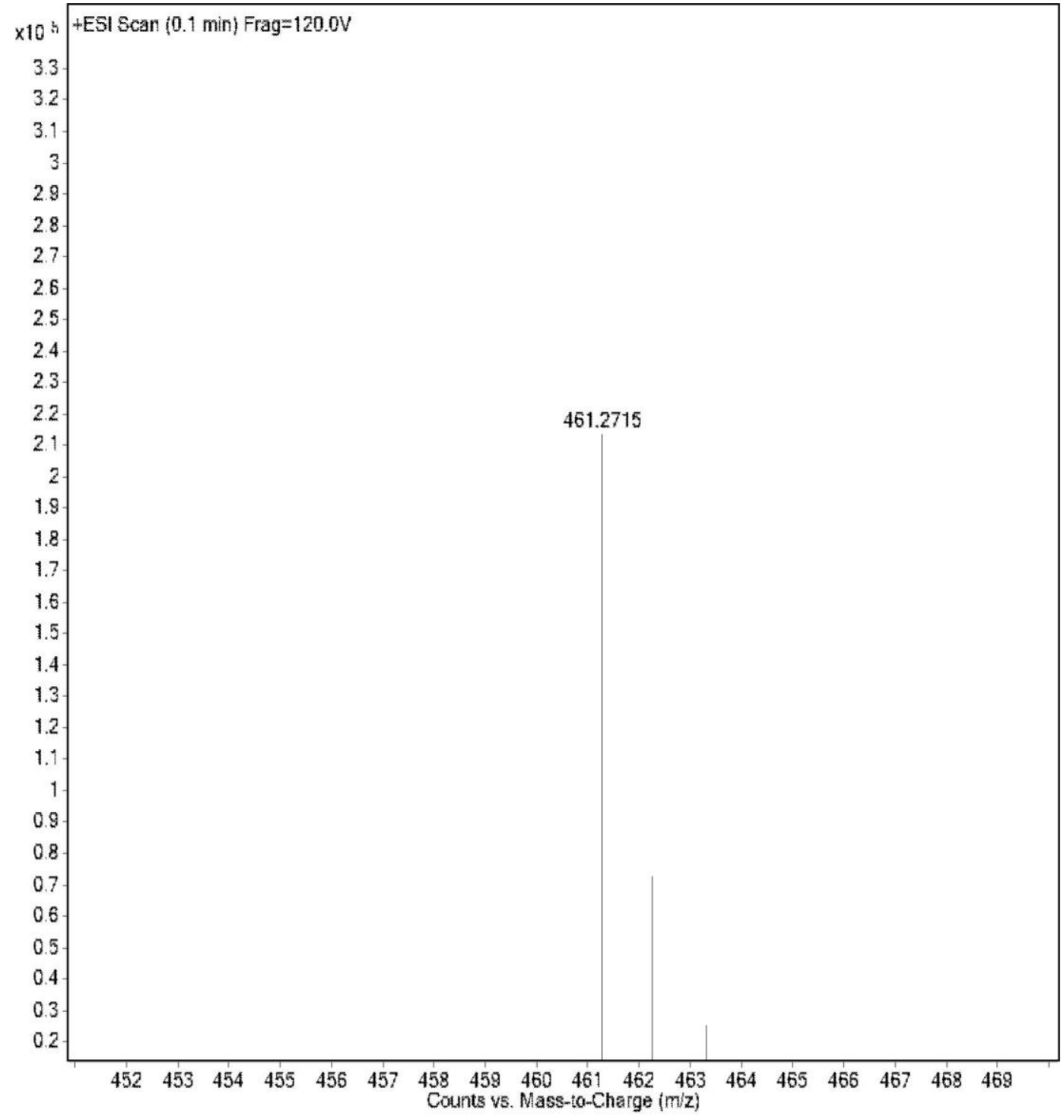

Figure S36. HR-MS (ESI ${ }^{+}$) of dye $\mathbf{1 d}$. 
Acquisition Parameter

Source Type ESI

Focus Not activ

Scan Begin

$50 \mathrm{~m} / \mathrm{z}$

Ion Polarity Positive

Set Capillary

Set End Plate Offset

$4500 \mathrm{~V}$

Scan End

$3000 \mathrm{~m} / \mathrm{z}$

Set Collision Cell RF

200.0 Vpp
Set Nebulizer $\quad 1.0 \mathrm{Bar}$
Set Dry Heater $\quad 180$ 發
Set Dry Gas
Set Divert Valve Waste

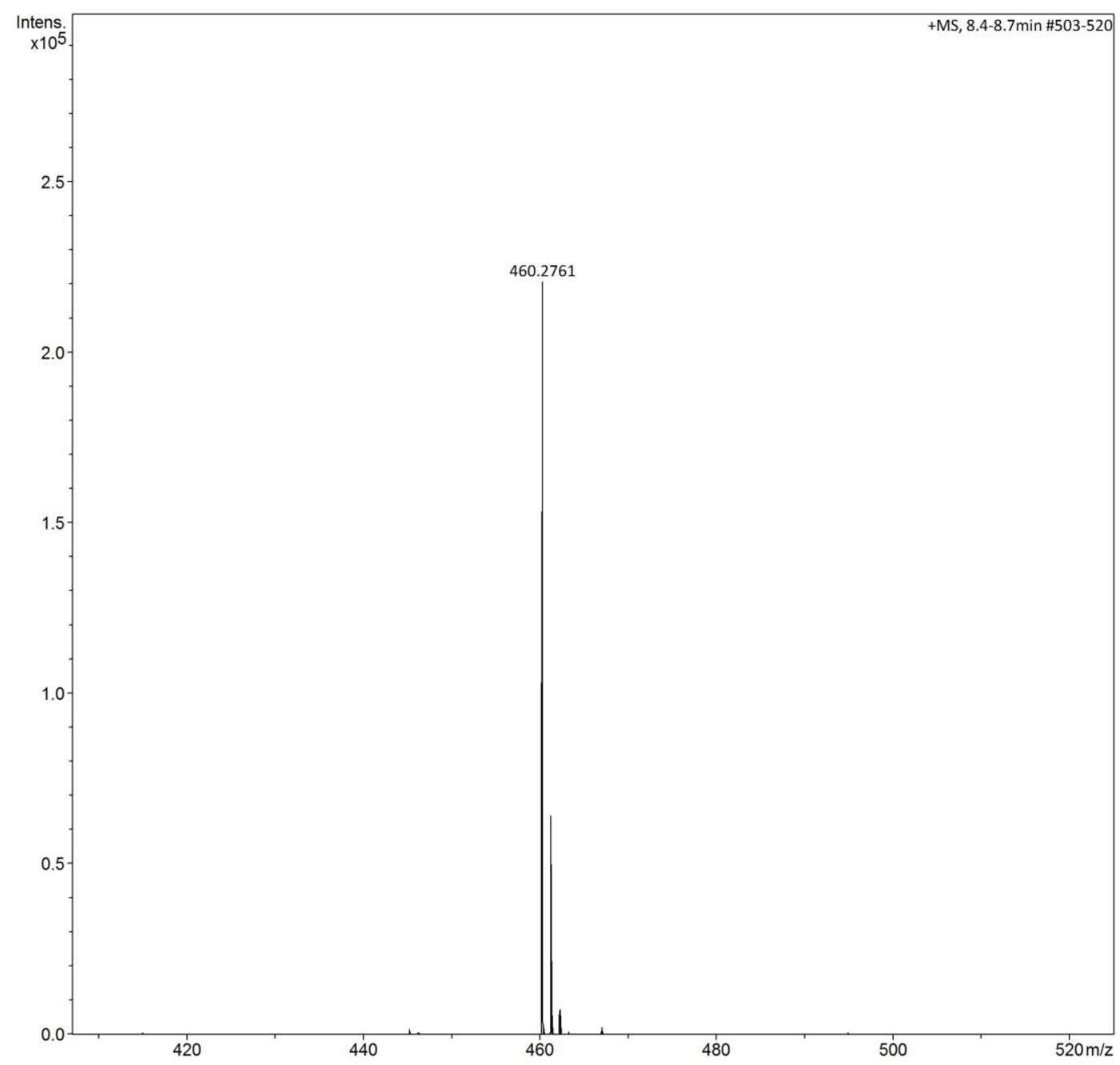

Figure S37. HR-MS $\left(\mathrm{ESI}^{+}\right)$of dye $\mathbf{1 e}$ 
Acquisition Parameter

Source Type

Focus

Scan Begin

Scan End

\section{ESI}

Not active

$50 \mathrm{~m} / \mathrm{z}$

$3000 \mathrm{~m} / \mathrm{z}$
Ion Polarity

Set Capillary

Set End Plate Offset $\quad-500 \mathrm{~V}$

Positive

$4500 \mathrm{~V}$

Set Collision Cell RF

$\begin{array}{ll}\text { Set Nebulizer } & 1.0 \mathrm{Bar} \\ \text { Set Dry Heater } & 180 \text { 癈 } \\ \text { Set Dry Gas } & 4.0 \mathrm{I} / \mathrm{min} \\ \text { Set Divert Valve } & \text { Waste }\end{array}$

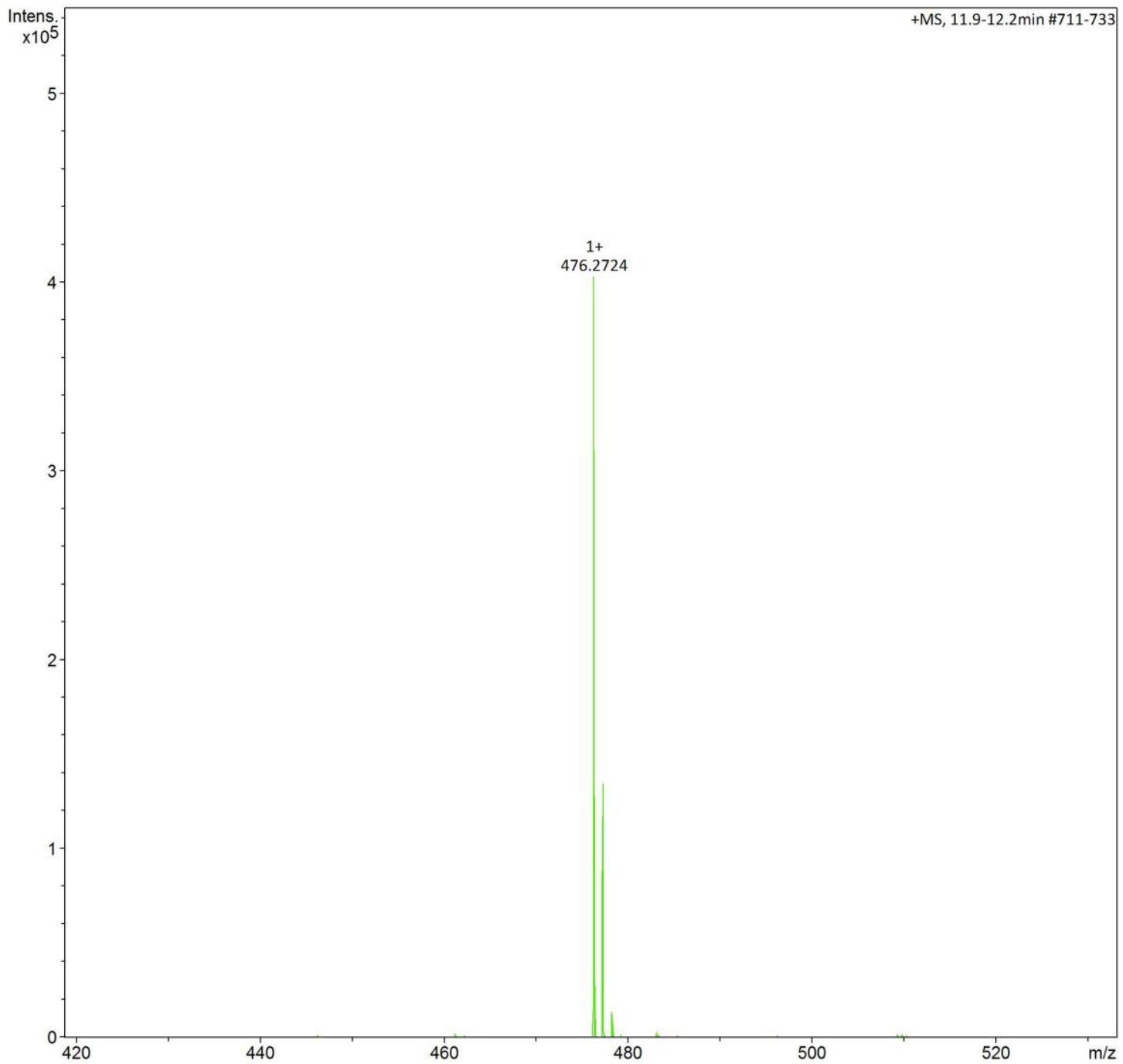

Figure S38. HR-MS $\left(\mathrm{ESI}^{+}\right)$of dye 1f.

\section{References}

(1) Chen, B.; Li, C.; Zhang, J.; Kan, J.; Jiang, T.; Zhou, J.; Ma, H. Chem. Commun. 2019, 55, 7410-7413.

(2) Sha, X.-L.; Niu, J.-Y.; Sun, R.; Xu, Y.-J.; Ge, J.-F. Org. Chem. Front. 2018, 5, 555-560.

(3) Rurack, K.; Spieles, M. Anal. Chem.2011, 83, 1232-1242. 